\title{
Oxygen sensing mechanisms across eukaryotic kingdoms and their roles in complex multicellularity
}

\begin{abstract}
Summary
Background

Animals and land plants are the most diverse complex multicellular lifeforms on Earth and their success intricately links a capacity for adhering cells to perform different tasks at different times. The performance of cell tasks, however, can be both dependent on and challenged by oxygen. Oxygen acts as the final electron acceptor for aerobic respiration but also participates in reactions to generate metabolites and structural macromolecules, and, recently, has come to the fore for its signaling role in developmental programs in animals and plants. Today, the relative oxygen concentration within multicellular organisms integrates information about cell position, metabolic state and environmental conditions. For the rise of complex life, the capacity to link oxygen perception to transcriptional responses would have allowed organisms to attune cell fates to fluctuations in oxygen availability and metabolic needs in a spatiotemporal manner.
\end{abstract}

\section{Advances}

Recent discoveries of oxygen sensing mechanisms in different eukaryotic kingdoms allow us to compare molecular strategies dedicated to this task and the outputs that these produce. Remarkably, higher plants and animals converged, from a functional perspective, to recruit dioxygenase enzymes to post-translationally modify transcriptional regulators for proteasomal degradation at the relatively 'normoxic' conditions. In this way, transcriptional responses can be repressed at higher oxygen (which is context dependent) but specifically elicited under hypoxia. The mitigation of the effects of prolonged hypoxia are also similar in animals and plants: reduction of metabolic rate, avoiding toxicity of anaerobic by-products and preventing cell injury upon reoxygenation. Recent geological and phylogenetic investigations allow us to reconstruct the origin of such molecular switches in the eukaryotic clade and compare it to the development of organ-grade multicellularity. The results support the perspective that oxygen consuming enzymes evolved sensory functions depending on the contingent requirements imposed by the environment and developmental programs. Considering that these sensing machineries evolved at a time (in the Neoproterozoic and early Paleozoic eras) when atmospheric oxygen concentrations were significantly lower than today, and in marine settings where redox is prone to vary, they may have played a major role in guiding development and homeostasis in response to endogenous oxygen dynamics. The broad scope of oxygen sensing and response machineries for multicellular success is further highlighted when hijacked during tumorigenesis to support uncontrolled growth in a variety of conditions and stresses.

\section{Outlook}

The broad role of oxygen sensing systems in the survival and evolution of complex multicellular life requires further exploration, including into the commonality and conservation of the oxygen sensing machineries. That higher plants and animals adopted alternative solutions to direct their primary hypoxia responses, despite their ancestors likely being equipped with the same enzymatic repertoire, may describe differences in their respective environmental, cellular and organismal features and histories. Broadly, by shifting focus from exploring oxygen sensing mechanisms as primarily a response to oxygen shortage for aerobic respiration, we can potentially reveal novel ways in which these systems can be manipulated for clinical and agricultural benefit. By such an approach, we will gain further insight to their broad scope, and the challenges that multicellular life is exposed to, today as in geologic history. 


\title{
Title: Oxygen sensing mechanisms across eukaryotic kingdoms and their roles in complex multicellularity
}

\author{
Authors: Emma U. Hammarlund ${ }^{1,2^{*}}$, Emily Flashman ${ }^{3}$, Sofie Mohlin ${ }^{1,4}$, Francesco Licausi ${ }^{5,6,7^{*}}$
}

\section{Affiliations:}

$5{ }^{1}$ Translational Cancer Research, Lund University Cancer Centre at Medicon Village, Lund University, Lund, SE.

${ }^{2}$ Nordic Center for Earth Evolution, University of Southern Denmark, Campusvej 55, 5230 Odense M, DK.

${ }^{3}$ Chemistry Research Laboratory, University of Oxford, Mansfield Road, Oxford OX1 3TA, UK.

${ }^{4}$ Division of Pediatrics, Department of Clinical Sciences, Lund University, Lund, SE.

${ }^{5}$ Department of Plant Sciences, University of Oxford, South Parks Road, OX1 3RB, UK.

${ }^{6}$ PlantLab, Institute of Life Sciences, Scuola Superiore, Sant'Anna, 56124 Pisa, IT.

${ }^{7}$ Department of Biology, University of Pisa, 56126 Pisa, IT

"These authors contributed equally to the work. Correspondence to emma.hammarlund@med.lu.se or f.licausi@sssup.it.

One sentence summary: Oxygen sensing mechanisms demonstrate convergent evolution and central functions for Earth's most complex organisms - animals and plants.

Abstract: Oxygen sensing mechanisms of eukaryotic multicellular organisms coordinate hypoxic cellular responses in a spatiotemporal manner. While this capacity partly allows animals and plants to acutely adapt to oxygen deprivation, its functional and historical roots in hypoxia emphasize a broader evolutionary role. For multicellular lifeforms that persist in settings with variable oxygen concentrations, the capacity to perceive and modulate responses in and between cells is pivotal. Animals and higher plants represent the most complex lifeforms that ever diversified on Earth, and their oxygen sensing mechanisms demonstrate convergent evolution from a functional perspective. Exploring oxygen sensing mechanisms across eukaryotic kingdoms can inform us on biological innovations to harness ever-changing oxygen availability at the dawn of complex life, and its utilization for organismal development.

\section{Main Text:}

\section{Introduction}

The rise of Earth's most complex and sizable lifeforms - animals and land plants - remains enigmatic. Out of all of life's diversity, only animals and land plants have multiple organs like a brain and lungs or roots and leaves. Animals and plants therefore represent two uniquely successful versions of complex multicellularity, but the inferred causes for their success are opposing. While the rise of animals is commonly explained as a result of environmental change (increased oxygen) that unleashed the full potential of biological innovations (Nursall 1959, Berkner and Marshall 1965), the rise of plants is explained with biological innovations unleashing a capacity to live with environmental change (e.g. in aquatic or terrestrial environments) (Morris et al. 2018). However, recent and transdisciplinary insights demonstrate that animals and land plants share a uniquely versatile capacity to perceive and respond to 
fluctuating oxygen conditions (Gibbs and Holdsworth 2020, Licausi et al. 2020). Here, we propose that the acquisition of the capacity to perceive and respond to the variable presence of oxygen must have been central to the rise of complex life. To evaluate this hypothesis, we consider two worlds in parallel, and bridge their information - the modern world, in which an oxygen sensing capacity provides key functions to animals and plants, and the historic one, in which neither oxygen sensing mechanisms nor complex multicellular organisms were yet fully in place.

Free oxygen profoundly affects eukaryotic cells. On the one hand, molecular oxygen acts as a terminal electron acceptor that yields unprecedented energy during aerobic respiration and builds metabolites. On the other hand, reactive chemical species containing oxygen can change the configuration and function of nucleic acids, sugars, lipids, proteins, and metabolites. The paramount impact that fluctuating oxygen availability has for cell function and constitution makes the capacity to perceive oxygen utterly important for any eukaryotic organism, especially when the organism is multicellular. Complex multicellular organisms are defined by their persistent three-dimensional organization in which adhering cells can perform different tasks of labor at different times (Grosberg and Strathmann 2007, Arendt et al. 2016, Sebé-Pedrós et al. 2017). Cell clustering per se represents a state which buffers environmental chemical fluctuations and stabilizes internal gradients. However, internal oxygen gradients also change dynamically as a function of cell respiration. Cells will therefore experience different oxygen availability depending on both their spatial and temporal (spatiotemporal) position. These fluctuations in dynamic internal oxygen gradients combined with oxygen's power to affect cell functions, therefore, make the capacity to perceive oxygen an adaptation with considerable but yet underappreciated scope. If the capacity to sense oxygen is combined with specific responses to different oxygen concentrations, it would also facilitate spatiotemporal induction of different cellular functions.

Oxygen sensing is the ability by which modern organisms detect changes in the amount of oxygen within and between cells, coupled to a context-dependent response. As of today, oxygen sensing is commonly described as the acute response to oxygen concentrations below the respiratory requirements (hypoxia) of the host. This allows tissue homeostasis when, for example, a muscle experiences oxygen depletion during a fast run or when a root's access to oxygen is blocked by waterlogging. However, while the necessity of an acute response to hypoxia makes sense to us, as obligate aerobes, the normalcy of hypoxia offers another perspective: oxygen levels below the ambient concentration can be argued to be normal for certain tissues in plants (van Dongen and Licausi 2015) and most tissues in animals (Webster and Abela 2007, McKeown 2014). Hypoxia also prevailed globally at the time in Earth history when oxygen sensing evolved, with atmospheric oxygen concentrations presumably below 5\% (Bergman et al. 2004, Canfield 2014). The hypoxia-response machineries reach beyond coping with hypoxia, to coordinate different cell fates (future identities and tasks) in accordance with - and despite - oxygen availability and fluctuations.

Here, we present a broad look at oxygen sensing mechanisms across eukaryotic kingdoms and time, to place their role within the context of evolving complex multicellularity. We describe the rarity of complex multicellularity over the history of life, the prevalence of fluctuating environmental oxygen conditions, and the necessity to perceive these fluctuations. We then review the different known oxygen sensing mechanisms and their roles for modern forms of multicellularity, discussing the conceptual gaps that present opportunities to explore the hierarchical order, evolution, and impacts of cellular oxygen sensing.

\section{The historic arena: hypoxic, variable, and largely devoid of multicellularity}

Complex multicellular organisms are rare in the long history of life when compared to the diversity of unicellular organisms. The diversity of unicellular prokaryotes (Archaea and Bacteria) and eukaryotes (protists in the broad sense including Protozoa, Chromista and Archezoa) is estimated to supersede the collective phylogenetic diversity of animals, plants and fungi by at least an order of magnitude (Whitman et al. 1998, IUCN 2014). The degree of organismal complexity can also be compared by the diversity of cell types that make up tissues. With that view, vascular plants and particularly animals are by far more complex than all other known organisms (Valentine et al. 1994, Graham et al. 2000, Bell 
and Mooers 2008). Simple multicellularity is an aggregation of cells where spatiotemporal coordination of labor is lacking, and this has evolved independently multiple times (Knoll 2011). Complex multicellularity however has diversified only six times across geologic history: three within the plant kingdom (red algae, brown algae, and land plants), twice in the kingdom of fungi, and once as the animal kingdom (Sebé-Pedrós et al. 2017). Out of these events, only animals and land plants (Embryophyta) form organ systems. Although the ages of the first or last common eukaryotic ancestor as well as when eukaryotic kingdoms diverged are debated, the diversification of eukaryotes is considered late by most. With records of molecular clock estimates and microfossils suggesting it took at least a billion years before the diversification of the animal and plant (Viridiplantae and Streptophyta) kingdoms began some 0.8 billion years ago (giga annum, Ga) in the Cryogenian Period (Porter 2004, Butterfield 2015). Thereafter, animal diversity 'exploded' in the Cambrian and Ordovician periods (0.54-0.44 Ma) which was also when land plants (Embryophyta) and vascular plants (Tracheophyta) originated (Porter 2004, Morris et al. 2018) (Fig. 1). Thus, organ-grade complex multicellularity evolved only twice, both relatively late in Earth history. The rarity of successful transitions from unicellular eukaryotes to complex multicellular life suggests that cellular and environmental components necessary to facilitate persistent and complex multicellularity are difficult to align. One inferred environmental component and culprit for the rise of particularly animal diversity is how environments became permissive by increasing free oxygen (Nursall 1959, Berkner and Marshall 1965, Knoll and Carrol 1999).

Free oxygen began to build up in the atmosphere about halfway through Earth's 4.6 Ga history, instigated by the cyanobacterial capacity for oxidative photosynthesis. The signs of free atmospheric oxygen are visible in the rock record at $\sim 2.45 \mathrm{Ga}$, via indirect geochemical evidence (Farquhar et al. 2000). Prior to this, however, free oxygen was produced and seemingly present in marine shallow (shelf) settings (Kendall et al. 2010) at the trace concentrations that allow biosynthesis of steroids (Waldbauer et al. 2011). After $2.45 \mathrm{Ga}$ and for more than the following two billion years, atmospheric oxygen concentrations were as low as what oceanographers call severely hypoxic $(<2 \%)$ or hypoxic ( $<5-7 \%$, albeit this is context dependent, see Sperling et al. 2015) (Canfield 2014). Not until 150 million years after the rise of animals and plants, in the Silurian or Devonian periods did global oxygenation approach modern levels (Lenton et al. 2016) (Fig. 1). Over the Cambrian and Ordovician periods when animals diversified and vascular plants originated, geochemical reconstructions estimate that the atmosphere had 2-5\% or at most $10 \% \mathrm{O}_{2}$ (Bergman et al. 2004, Dahl et al. 2010, Canfield 2014,

120 Krause et al. 2018). Thus, conditions at the time when animals and plants and their oxygen sensing mechanisms originated and diversified can be considered hypoxic by today's standards.

Variability of oxygen concentrations is a physical imperative on Earth's surface. Even today, when the atmosphere is richly oxygenated (21\%), oxygen levels vary dramatically both in soil and within the ocean. Respiration of biomass may consume oxygen faster than it is replenished, whether in soil or water (in water, gas diffusion is four orders of magnitude slower than in air). Animals and green plants evolved in the ocean, where production and respiration of biomass together with physical mixing, e.g. winds and waves, result in constantly variable environmental oxygen conditions. The long history of oxygen fluctuations in shallow marine niches would have posed a ceaseless challenge to nascent multicellular organisms with limited capacity to perceive and respond to these variations. Thus, both the challenges and opportunities for eukaryotic life to intermittently encounter free oxygen attributes an evolutionary importance to the cellular mechanisms that perceive it. Prior to the development of cellular mechanisms to perceive and to orchestrate organismal responses to changes in oxygen conditions, complex multicellular life would have struggled to sustain in niches with fluctuating conditions on the Earth's surface (Hammarlund 2019).

\section{The past and present of oxygen sensing}

Oxygen sensing acts as a transducer of hypoxic signaling, which is best illustrated by the primary hypoxia-response machineries in plants and animals. These machineries function through the action of oxygen-dependent enzymes which repress the operation of transcription factors (TFs). In an oxygendependent reaction, these enzymes catalyze a post-translational modification of the transcription factor that reduces its stability (Gibbs and Holdsworth 2020, Licausi et al. 2020). Oxic conditions therefore 
lead to degradation of these transcription factors and, hence, inactivity of the hypoxic responses. In hypoxic conditions, however, reduced activity of the oxygen sensing enzymes allows stabilization of the TFs, which direct the response to hypoxia by upregulating a suite of genes that trigger adaptation. Enzymes are particularly suited to act as sensors as their rate of activity is proportional to the amount of substrate available, i.e. they can elicit a graded response to oxygen.

\section{Sensing through Fe(II)/2OG-dependent oxygenases}

The first identified and most characterized hypoxia-response machinery is the system of Hypoxia Inducible Factors (HIF) in animals, the discovery of which was recognized with the 2019 Nobel Prize in Physiology or Medicine (2019). HIFs are heterodimers consisting of alpha subunits and the aryl hydrocarbon receptor nuclear translocator (ARNT), or beta subunit. HIF- $\alpha$ subunits are stabilized at hypoxia, leading to the transcription of hundreds of genes which promote adaptive responses. In physiologically oxic conditions, however, the oxygen-dependent prolyl hydroxylase enzymes (PHDs) catalyze hydroxylation of specific prolyl residues in HIF- $\alpha$ proteins that enable their recognition by ubiquitin ligase complexes (commonly the von Hippel Lindau (VHL) protein) and subsequent degradation via the proteasome (Kaelin and Ratcliffe 2008). A second hydroxylase enzyme (Factor Inhibiting HIF, FIH) catalyzes hydroxylation of an Asparagine (Asn) residue in HIF- $\alpha$ to reduce the trans-activation capacity of HIFs. The PHDs and FIH are Fe(II), 2-oxoglutarate (2OG) and oxygendependent enzymes, whose rate of activity is sensitive to oxygen availability, particularly the PHDs (Epstein et al. 2001, Hirsila et al. 2003, Tarhonskaya et al. 2014). This means that even a small decrease

160 in oxygen availability can potentially result in a reduction in HIF hydroxylation to enable HIF stabilization and activation of its transcriptional response (Fig. 2). While PHD-like enzymes are conserved even in bacteria (Scotti et al. 2014) and fill an oxygen-dependent regulatory role in yeast (Loenarz et al. 2014), their oxygen sensing function appears refined with the involvement of HIF and the ubiquitin-protesome system (Loenarz et al. 2011). All eumetazoans (animals with bilateral and radial symmetry) except the ctenophores possess the HIF-1 $\alpha$ subunit, while only vertebrate animals possess the HIF-2 $\alpha$ subunit (Rytkönen et al. 2011, Hammarlund et al. 2018).

Eukaryotes and prokaryotes involve Fe(II)/2OG-dependent dioxygenases in a number of important biological functions (Islam et al. 2018). Although the catalytic rate of all these enzymes depends on oxygen availability, whether or not these enzymes can act as oxygen sensors in the hypoxia-response machinery depends on two factors. Firstly, whether the impact of their activity is transduced through their substrates to induce a response, and secondly, whether their rate of activity is limited by the range of oxygen concentrations present in the cell. Despite overall conservation of enzyme structure and catalytic mechanism, different $\mathrm{Fe}(\mathrm{II}) / 2 \mathrm{OG}$-dependent dioxygenases are rate-limited by oxygen at different concentrations. The PHDs are rate-limited at relatively high oxygen concentrations. FIH activity can on the other hand tolerate mild hypoxia for HIF Asn-hydroxylation and even more severe hypoxia for non-HIF substrates (Tarhonskaya et al. 2015). Other members of this enzyme family are restricted only at very low oxygen concentrations to initiate an adaptive response at severe hypoxia. For example, ten-eleven translocation (TET) DNA demethylases only lose their activity in severely hypoxic tumors, leading to DNA hypermethylation (Thienpont et al. 2016).

180 A subset of $\mathrm{Fe}(\mathrm{II}) / 2 \mathrm{OG}$ dependent oxygenase enzymes, the Jumonji C (JmJC) domain containing histone lysine demethylases (KDMs), has been reported to demonstrate an $\mathrm{O}_{2}$-sensing role across a broader range of oxygen concentrations. The status of histone methylation can impact chromatin packing and affect transcriptional responses, by regulating access of transcription factors to promoter regions. Recent studies have connected the $\mathrm{O}_{2}$-sensitivity of some $\mathrm{KDMs}$ with altered histone methylation status in hypoxia (Hancock et al. 2015, Hancock et al. 2017, Batie et al. 2019). Of these, KDM5A and KDM6A play a role in cell differentiation and fate restriction and have implications for tumorigenesis (Chakraborty et al. 2019).

In yeast and protozoa, certain $\mathrm{Fe}(\mathrm{II}) / 2 \mathrm{OG}$ dioxygenases also play $\mathrm{O}_{2}$-sensing roles. In fission yeast, a sterol regulatory element-binding protein transcription factor (Sre1) promotes adaptation to hypoxic conditions, and the activity of Sre1 is controlled by an oxygen sensitive $\mathrm{Fe}$ (II)/2OG-dependent 
dioxygenase, Ofd 1 (Hughes and Espenshade 2008). This mechanism controls cholesterol synthesis and uptake in yeast (as does its homologue in animals; Espenshade and Hughes 2007). In protozoa, oxygen sensing prolyl hydroxylases catalyze hydroxylation of S-phase kinase-associated protein 1 (Skp1), an essential subunit of a ubiquitin-ligase complex. This hydroxylation transduces the oxygen-dependent regulation of different developmental stages in the protozoan life cycle. At these stages, certain oxygen concentrations work as environmental triggers and correspond to concentrations where the enzymes are rate limited (Xu et al. 2012). This rate limitation suggests that the oxygen sensitivity of these reactions has been fine-tuned and advantageous during evolution. The function of this oxygen sensitivity is clear from slime molds (Mycetozoa, normally solitary amoebae) where it facilitates regulation of cells of different differentiation states during the formation of their multicellular fruiting bodies (Dickinson et al. 2011).

It should be noted that prokaryotes also have a variety of $\mathrm{Fe}(\mathrm{II}) / 2 \mathrm{OG}$-dependent oxygenases with a wide range of roles, including in protein translation (Chowdhury et al. 2014, Scotti et al. 2014). Broadly, none of these has yet been reported as being highly sensitive to oxygen (except for a thermophilic ribosomal oxygenase under high temperature conditions Sekirnik et al. 2018). Bacterial oxygen sensing is instead achieved via different mechanisms involving either conformational change of a DNA-binding protein upon $\mathrm{O}_{2}$-binding, or phosphorylation cascades that result in transcriptional upregulation in hypoxia. Bacterial oxygen sensing is described in detail in several reviews (e.g. Taabazuing et al. 2014).

\section{Sensing through thiol dioxygenases and the Arg branch of the N-degron pathway}

210 Vascular plants exploit a different hypoxia-response machinery, albeit with features in common with the HIF system of eumetazoans. Here, constitutively expressed transcription factors belonging to the group VII of Ethylene Response Factor family (ERF-VIIs) are stabilized in hypoxia to enable transcription of a suite of genes which promote adaptive responses (Licausi et al. 2011, Gibbs et al. 2018). In physiologically oxic settings, the ERF-VIIs are degraded via the Arg/N-degron pathway, a process of degradation signaling in which the identity at the $\mathrm{N}$-terminus of a protein dictates its stability (Bachmair et al. 1986, Varshavsky 2019). Plant Cysteine Oxidases (PCOs) catalyze dioxygenation of cysteinyl (Cys) residues at N-termini (Nt) of the ERF-VII transcription factors (Weits et al. 2014, White et al. 2017), which are subsequently arginylated by Arginyl-transferases (ATE) and then presumably recognized by the ubiquitin ligase Proteolysis 6 (PRT6) (Dissmeyer 2019). This recognition leads to the degradation of the ERF-VIIs. So, in plants, PCOs act as sensors while the ERF-VIIs transduce the hypoxic signal into a response.

PCOs are Fe(II)-dependent thiol dioxygenases whose rate of activity with respect to ERF-VII oxidation is sensitive to oxygen availability (White et al. 2018), similar to the metazoan PHDs involved in HIF regulation. Apparently, these two hypoxia-response mechanisms have evolved separately but fulfil similar roles. Unlike the HIF hydroxylases, for which activity towards non-HIF substrates is uncertain (Cockman et al. 2019), the PCOs appear to have multiple substrates, including Little Zipper Protein 2 (ZPR2) and Vernalization 2 (VRN2) (Gibbs et al. 2018, Weits et al. 2019). There are therefore several 'response' components controlled by the oxygen sensing PCOs. This means that a hypoxic response can be transduced via several pathways, depending on the cellular context. Although the degree of 230 oxygen sensitivity of the PCOs towards these and other alternative substrates is yet unreported, the hypoxia dependence of this function is clear. ERF-VIIs first appeared in vascular plants and ZPR2 and VRN2 became Cys-initiating proteins in flowering plants (angiosperms) (Holdsworth and Gibbs 2020, Weits et al. 2020). On the other hand, the enzymatic asset of the Arg/N-degron pathway and PCOs required to operate oxygen dependent degradation of Nt-Cys-degrons can be traced back to unicellular eukaryotic ancestors of plants and animals (Holdsworth and Gibbs 2020). Thus, it can be hypothesized that other Cys-initiating proteins control the hypoxia response in lower plants. In this perspective, the identification and characterization of Cys-initiating transcription factors is of particular interest.

Intriguingly from an evolutionary perspective, a human homologue of the PCOs, the enzyme 2aminoethanethiol dioxygenase (ADO), was recently identified as regulating the stability of certain N- 
et al. 2019). ADO acts as a separate human oxygen sensor via an equivalent mechanism to that of the PCOs in plants. ADO activity towards RGS4/5 is particularly $\mathrm{O}_{2}$-sensitive, with a rate-dependence close to that of the PHDs (Tarhonskaya et al. 2014). So far, no Nt-Cys-degron transcription factor has been identified as an ADO substrate, thus the 'response' component of this machinery does not amplify the transduction of the hypoxic signal similarly to HIF or ERF-VIIs. Nevertheless, the commonality in oxygen-dependent proteolysis mediated by thiol-dioxygenases in plants and animals is striking and may suggest the existence of an ancestral mechanism in early eukaryotes.

To summarize, these observations hint at both convergence and divergence of oxygen sensing machineries in complex multicellular eukaryotes. On the one hand, both metazoans and vascular plants converged to the aerobic degradation of constitutively expressed transcriptional regulators. The key sensory dioxygenases and protein substrates differ, but the proteostatic logic that enables the activation of adaptive responses is very similar. On the other hand, the presence of both enzymes in the plant and animal kingdoms indicate a preference towards either system, possibly to accommodate specific developmental, physiologic or metabolic requirements. In the evolutionary perspective of oxygen perception, it is remarkable that plant and animal species share few conserved mechanisms, when compared to the high diversity displayed in bacteria, archaea and fungi (Grahl and Cramer 2010, Taabazuing et al. 2014).

\section{The power of hypoxia-response machineries}

The roles of oxygen sensing mechanisms have been explored at the cellular, individual, and evolutionary levels, often under the assumption that hypoxia is a 'stress'. Here, however, we evaluate whether the adaptations provided by oxygen sensing allow cells and individuals to cope with fluctuations and internal gradients in oxygen availability on both temporal and evolutionary time scales. We also consider their capacity for spatiotemporal coordination of cell labor and fates.

\section{Guarding against oxygen fluctuations - homeostasis}

265 Oxygen concentrations perpetually fluctuate in Earth's surface environments as a function of consumption, diffusion and re-supply. Similarly, oxygen concentrations fluctuate within and outside of organisms, tissue, and cells. When oxygen concentrations are temporarily lower than the organism's respiratory requirements, responses act to maintain homeostasis by reversal or mitigation. Homeostatic responses to hypoxia typically involve mRNA reprogramming, which represses energetically 270 expensive pathways and upregulates those associated with adaptation or avoidance (Lendahl et al. 2009, Mustroph et al. 2010, Tian et al. 2017).

Temporal oxygen deficit for metabolic reactions requires, on the one hand, activation of alternative pathways that minimize oxygen consumption (Seagroves et al. 2001, Bui et al. 2019) but, on the other, might also induce the activity of essential enzymes that use oxygen as a substrate (Lee et al. 1997, Klinkenberg et al. 2014). When severe hypoxia shifts sugar metabolism towards substrate-level phosphorylation at the expense of the oxidative pathway, this is achieved by facilitating carbon entry into the glycolytic pathway (Mustroph et al. 2010), putting on the brakes to pyruvate channeling into the tricarboxylic acid (TCA) cycle and redirecting it to fermentative reduction. Albeit different in eukaryotic kingdoms, these ancillary reactions sustain the carbon flux through glycolysis by the regeneration of oxidized $\mathrm{NAD}^{+}$and, concomitantly, prevent the inhibition of glycolysis by its own products. The majority of animals as well as some fungi reduce pyruvate to lactate by means of hypoxiainducible lactate dehydrogenase (LDH) (Alberti 1977), while yeasts rely exclusively on alcohol fermentation by a two-reaction pathway that decarboxylates pyruvate and reduces the resulting acetaldehyde (Dashko et al. 2014). In Viridiplantae, both metabolic strategies of reducing pyruvate, either by LDH or by alcohol fermentation, are activated under hypoxia, with additional contribution of formate, hydrogen, acetate, and alanine synthetic pathways (Yang et al. 2015, António et al. 2016). Higher plants evolved towards a preference for ethanol fermentation since lactic acid deprotonation contributes to cytosolic acidosis and thus jeopardizes cellular functioning and integrity. Removal of fermentative products is also facilitated in the animal and plant kingdoms, for instance with the 
upregulation of lactate exporters (Ullah et al. 2006, Choi and Roberts 2007)). In contrast to lower species where fermentation appears controlled by substrate availability or post-translational regulation, genes coding for enzymes and transporters involved in this metabolic adaptation to hypoxia are found incorporated in the main hypoxia response in metazoans and higher plants (Mustroph et al. 2010, Bui et al. 2019). From this perspective, transcriptional regulation of the genes coding for this metabolic adaptation is a recent acquisition, concomitant to the increase in developmental complexity in both kingdoms. Thus, convergence towards this regulation seems to offer an ecological advantage for complex multicellular systems to cope with the temporal offset between metabolic requirements and oxygen availability (Fig. 3).

Counteracting hypoxia by reoxygenation is also activated in animal and plant tissues. In most vertebrates, for example, this is attained via the local generation of new blood vessels (angiogenesis) and of synthesis of erythrocytes that carry oxygenated hemoglobin (Krock et al. 2011). Plants, instead, lack a dedicated oxygen distribution system and thus certain species which are adapted to flooding acquired the ability to form hollow paths along stems and roots (aerenchyma), for unrestricted gas diffusion from above-water organs to submerged tissues (Yamauchi et al. 2013). When the whole plant is underwater, rapid growth of stems and leaves can be deployed for emergence and ensure oxygen acquisition (Hattori et al. 2009). Neither aerenchyma formation nor the elongation of organs are controlled by oxygen availability directly but rather through the gas hormone ethylene, whose synthesis is enhanced by submergence (Cohen and Kende 1987, He et al. 1996).

Fluctuations in oxygen are concomitant with fluctuations in reactive oxygen species (ROS) and reactive nitrogen species (RNS). Indeed, a burst of hydrogen peroxide $\left(\mathrm{H}_{2} \mathrm{O}_{2}\right)$ and nitric oxide (NO) has been reported to occur in animal and plant cells when these are challenged by severe oxygen deficiency (Galkin et al. 2007, Pucciariello et al. 2012, Chen et al. 2018, Gupta et al. 2020). Additional and more severe ROS accumulation is also expected as normoxic conditions are restored. Genes regulated by HIFs and ERF-VII in animals and plants, respectively, code for scavengers of both ROS and NO, as well as enzymes involved in redox homeostasis, such as glutathione peroxidase, superoxide dismutase, glutathione S-transferases and thioredoxins (Dengler et al. 2014, Giuntoli et al. 2017). In turn, ROS and NO contribute to HIF and ERF-VII regulation at the transcriptional and post-translational level in animal and plant cells, respectively (Hendrickson and R. 2015).

In conclusion, while strategies to reverse the effects of short-term hypoxia are kingdom specific (i.e. reoxygenation), mitigation of the effects of prolonged hypoxia can be related to similar strategies in animals and plants: reduction of the metabolic rate, avoiding toxicity of anaerobic by-products and preventing cell injuries upon reoxygenation. Oxygen sensing machineries assist animals and plants in these strategies to cope with the imbalances that fluctuating oxygen availability causes to the cellular environment. Collectively, these systems contribute to the ability of multicellular organisms to maintain homeostasis.

\section{A capacity to modulate cell fate}

The importance of oxygen availability and gradients for cells to multiply and differentiate has been recognized for a long time, and therefore also to the cellular capacity to sense these. A wide range of oxygen concentrations have been measured across plant and animal organs and observed to vary throughout developmental stages (Zaidi et al. 2019, Weits et al. 2020). Mammalian embryogenesis occurs mainly at low oxygen concentration, and several types of stem and progenitor cells are embedded in hypoxic niches, where oxygen gradients drive their differentiation (Simon and Keith 2008). Similarly, in plants, the proliferative tissues responsible for producing new organs, the meristems, have also been shown to be embedded in hypoxic niches (Weits et al. 2019). Furthermore, detrimental cell growth hijacks the oxygen sensing machinery and may induce cellular responses contrary to what oxygen gradients would dictate. In solid tumors, the uncontrolled proliferation of cells and their active metabolism often exceed the delivery capacity of the surrounding blood vessels, thereby limiting oxygen availability (Muz et al. 2015). It is now twenty years since the discovery that the HIF system enables and supports tumorigenesis (Pugh et al. 1991, Semenza et al. 1991). Similarly in higher plants, 
tumor-like tissues, such as calli or galls, experience oxygen limitations and ERF-VIIs support the metabolism and proliferation of highly dividing and undifferentiated cells (Kerpen et al. 2019).

Clues from cancer - uncoordinated formation of multicellularity: The cancer field has put more emphasis on HIFs than any other field, owing to the contribution of these factors to the success of tumor multicellularity. HIF- $\alpha$ is produced and degraded in the cytoplasm and, when stabilized for long enough, translocates to the nucleus. Localization and functions for the HIF- $\alpha$ subunits however appear to differ (Keith et al. 2011). In the case of HIF-1 $\alpha$, non-degraded protein is more or less exclusively present in the nucleus. Its activity is rather uniform by how it induces target gene expression in response to hypoxia in virtually any cell. That HIF- $1 \alpha$ plays a reliable role in the immediate cellular response to hypoxia argues for its seminal role as an adaptation to acute oxygen fluctuations. HIF-2 $\alpha$, on the other hand, displays cytoplasmic in addition to nuclear localization (Holmquist-Mengelbier et al. 2006, Li et al. 2009, Persson et al. 2020). Insight from tumor multicellularity demonstrates that functions of HIF- $\alpha$ subunits are non-overlapping. While the HIF-1 $\alpha$ subunit, which is unique for all eumetazoans except ctenophores, can be regarded as a fast response to metabolic alterations, the vertebrate specific HIF- $2 \alpha$ subunit is demonstrated to contribute to the success of tumors by modulating cell fate. Albeit that HIF$2 \alpha$ also plays a modest role in metabolic regulation, its main functions are regulation of cell fate, cell immaturity (stemness), metastasis and to establish a hypoxia-mimicking phenotype in oxygenated milieus (pseudohypoxic niches) (Covello et al. 2006, Das et al. 2012, Comino-Mendez et al. 2013, Mohlin et al. 2017b).

The pseudohypoxic phenotype is a consequence of HIF-2 $\alpha$ accumulation in normoxic tumor cells, including such with the capacity to self-renew (a stem cell trait typically associated with hypoxia). Some of these HIF-2 $\alpha$ expressing cells are located in perivascular niches, despite their access to oxygen in these areas (Pietras et al. 2008, Li et al. 2009). This phenomenon is particularly well studied in the 365 cancer forms glioblastoma and neuroblastoma (Pietras et al. 2008, Li et al. 2009), where there are no correlations between HIF- $1 \alpha$ expression and outcome whereas expression of HIF- $2 \alpha$ predicts poor prognosis and distal metastasis. Importantly, it is not the collected expression itself that falls out as a predictor, but rather the presence of this small fraction of HIF- $2 \alpha$ positive perivascular tumor cells. These constitute a rare cell type within the tumor that co-express several stem cell markers, 370 strengthening HIF- $2 \alpha$ as a promoter of stemness. The link between the pseudohypoxic phenotype, stemness, and the formation of tumor multicellularity is also supported by how mutations in EPAS1 (encoding HIF-2 $\alpha$ ) directly induce tumor formation (Zhuang et al. 2012). As an example of the complexity of this protein, a HIF-2-specific inhibitor, PT2385 (Scheuermann et al. 2013), which prevents ARNT binding and transactivation capacity, does not affect downstream transcription, cell proliferation or in vivo tumor growth in neuroblastoma (Mohlin et al. 2017a, Westerlund et al. 2017, Persson et al. 2020). In glioma, HIF-2 $\alpha$ localizes to extra-nuclear polysomes to promote translation of a large but distinct set of proteins (Uniacke et al. 2012). These and other data suggest that the HIF-2 $\alpha$ protein displays additional, although as yet mainly unknown, functions. We thus know that HIF-2 $\alpha$ is expressed in the nucleus and cytoplasm, and in tumor cells located in perivascular niches. HIF- $2 \alpha$ has

380 ARNT independent functions and it is plausible that it forms complexes with proteins other than ARNT to initiate transcription. In addition, HIF-2 $\alpha$ might form protein complexes in the cytoplasm to promote translation, stabilization and secretion of proteins important for stemness, pseudohypoxic phenotypes and tumor cell metastasis. In essence, HIF-2 $\alpha$ appears to mediate a hypoxic or non-hypoxic cellular response - that associates with cell stemness - independently of surrounding oxygen concentrations.

Clues from coordinated multicellular development: Developmental pathways are affected by the hypoxic transcriptional regulators in both animals and plants. These regulators act as switches or 'pacemakers' of stem cell proliferation and differentiation.

390 During animal development, HIF-1 $\alpha$ and its binding partner ARNT are ubiquitously expressed, whereas HIF-2 $\alpha$ expression is more tissue- and time-restricted (Jain et al. 1998, Tian et al. 1998). In invertebrate animals, hypoxia and subsequent HIF-1 $\alpha$ accumulation are associated with growth and stem cell proliferation during development in fruit flies and mosquitos (Gregory et al. 2008, Valzania et al. 2018). In vertebrates, HIF-1 $\alpha$ is ubiquitously expressed throughout development and homozygous deletion is 
lethal (Iyer et al. 1998, Ryan et al. 1998). HIF-1 $\alpha$ and HIF-2 $\alpha$ are demonstrated to promote the generation of new blood vessels and branching of existing ones. However, EPAS1 appears to have evolved before the downstream erythropoietin gene (EPO), a promoter of increased systemic oxygen carrying capacity, and, now, HIF- $2 \alpha$ directly promotes erythrocyte differentiation from bone marrow progenitors (Haase 2013). During development, expression of HIF-2 $\alpha$ is temporally and spatially restricted. Endothelial cells display high expression of HIF- $2 \alpha$ continuously while cells of the developing sympathetic nervous system (SNS) express HIF- $2 \alpha$ mRNA and protein during discrete periods of mammalian development (Jain et al. 1998, Jögi et al. 2002, Mohlin et al. 2013). Indeed, the central roles by which the animal-specific HIFs regulate hypoxic cell functions is suggested to have facilitated primitive animals to cope, and fully access, oxic niches during evolution (Hammarlund et al. 2018).

In higher plants, developmental processes are intertwined with the activity of at least three classes of transcriptional regulators characterized by an exposed $\mathrm{N}$-terminal cysteine, which is regulated by the oxygen-dependent branch of the N-degron pathway. First, ERF-VIIs have been shown to repress

410 opening of the protective hypocotyl hook and cotyledon greening, as well as antagonizing hormone signaling in the root for timely shaping of its architecture (Abbas et al. 2015, Shukla et al. 2019). Second, the little zipper protein ZPR2 binds and inactivates Homeodomain III-type transcription factors, regulators of meristem maintenance and new organ formation (Weits et al. 2019). Third, VRN2 is assembled into the polycomb repressive complex 2 (PRC2) that represses gene expression through histone methylation (Gibbs et al. 2018). One of the best characterized targets of this complex is the FLOWERING LOCUS C gene, a repressor of the transition towards reproductive development in Arabidopsis.

Epigenetic control of developmental pathways via histone methylation in both kingdoms is also controlled, in part, by oxygen dependent KDMs. While recent reports confirmed the hypoxia sensitivity of members of this protein family in human cells, with consequences for differentiation in several cell line model systems (Shmakova et al. 2014, Hancock et al. 2015, Batie et al. 2019, Chakraborty et al. 2019), this has not yet been explored in the lineage of green plants. However, several JmjC-domain containing KDM proteins have been shown to control aspects of plant development in Arabidopsis, including germination, flowering and callus formation (Huang et al. 2016).

\section{Oxygen sensing machineries as adaptations for nascent multicellularity}

In all kingdoms of life, enzymes that detoxify ROS are ubiquitously present, which indicates that their evolution predated photosynthetic oxygenation (Siauciunaite et al. 2019). Indeed, ROS can be locally produced by abiotic photolysis on a largely anoxic planet, according to geochemical and geophysical studies of both Earth and Mars (Slesak et al. 2012). Continuous scavenging of ROS through enzymatic or metabolic assets, however, is likely to be costly for cells. Instead, the acquisition of mechanisms for perception and response would be of higher gain. This perception and response would engage detoxification only when oxygen and ROS levels exceeded a danger threshold and thus be metabolically cheaper. The multitude of oxygen sensing strategies in prokaryotes and eukaryotes probably reflects adaptation to environmental niches distinguished by oxygen dynamics, in addition to the regulation of specific metabolic needs (Taabazuing et al. 2014). The acquisition of mechanisms for ROS perception and scavenging would have pioneered the utilization of free oxygen as a resource. With a control of ROS detoxification, oxygen sensing machineries could also be co-opted to express oxygen requiring genes when this substrate is available, and conversely suppress them in favor of anaerobic strategies in case of hypoxia.

440 The convergent evolution in complex eukaryotes towards selective proteolysis of transcriptional regulators which control hypoxia responses suggests the superiority of this strategy over others that utilize free oxygen. In all cases considered, the recruitment of specific transcriptional regulators by oxygen-dependent regulatory pathways occurred long after the 'invention' of oxygen consuming enzymes that operate on amino acid residues (Rytkönen et al. 2011). These enzymes could have evolved from their original metabolic function towards a role as sensors. In turn, the transcriptional regulators 
acquired the specific residues that are substrates of the sensor enzyme in strategic positions to subdue the kinetics of the reaction to physiologically relevant oxygen levels. To constitutively synthesize transcriptional regulators is also costly, but the cost can be balanced by the advantage of rapid activation once degradation is inhibited. In contrast, bacteria exploit post-translational regulation that is faster and less energy demanding, such as phosphorylation or dimerization (Taabazuing et al. 2014). This type of regulation, however, is not as effective or can possibly not guarantee a sufficient level of specificity. Indeed, the oxygen sensing systems in plants and animals are fine-tuned by several layers of modification, although they all seem to be subordinated to the proteolytic system. For example, while most translated HIF- $\alpha$ proteins are proteosomally degraded in oxic conditions via PHD/VHL mediated ubiquitination, a second layer of HIF regulation is driven by FIH, which catalyzes oxygen-dependent asparagine hydroxylation of HIF- $\alpha$. This second layer prevents the interaction between HIF- $\alpha$ and transcriptional activators. That FIH hydroxylates the asparagine motif less efficiently on HIF-2 $\alpha$ than on HIF-1 $\alpha$ could be one molecular explanation to why HIF- $2 \alpha$ is stabilized at higher oxygen concentrations (Bracken et al. 2006, Tarhonskaya et al. 2015). In essence, although the road to proteolysis can be retarded or distinctly coupled to intervals oxygen concentrations, the oxygen sensing machineries across eukaryotic kingdoms master the route along which protein is degraded by oxygen.

The commonality between organisms that exploited selective proteolysis as a solution to oxygen sensing resides in their complex multicellularity. Remarkably, HIF- $\alpha$ and ERF-VII and the regulatory proteins involved in their oxygen-dependent regulation are, at the outset, expressed and, subsequently degraded. This hints at the need for a unified system to perceive and interpret oxygen gradients that are unavoidably generated throughout growth and development. As compared to diffusible signal molecules produced endogenously, such as hormones, molecular oxygen provides a faster and more direct connection to the metabolic needs of aerobic cells. Indeed, within a persistent three-dimensional organization where respiration and transport regulate the mass balance of oxygen, cells are continuously exposed to variable oxygen concentrations depending on their position in space and time. The multiple layers of oxygen perception and response demonstrate a capacity by which this variability is recorded and translated during growth, development, and activities of daily living in the eukaryotic kingdoms with complex multicellularity. This capacity appears more restricted in protozoa and fungi that also demonstrate lower both phenotypic and cell type diversity than animals or vascular plants. In all cases, however, the oxygen sensing mechanisms contribute to the spatiotemporal induction of cellular functions, which is one of the defining features of complex multicellular life (Grosberg and Strathmann 2007, Arendt et al. 2016, Sebé-Pedrós et al. 2017) (Fig. 4).

\section{Conceptual gaps}

The role of oxygen sensing for complex multicellular life and evolution appears crucial but conceptual gaps remain on several layers. On the biomolecular and cellular level, for example, the presence of NtCys-degron transcription factors that are ADO substrates could inform us about the most ancestral of oxygen sensing strategies. Also, the existence of parallel oxygen sensing strategies based on 2-OG dependent oxygenases, such as KDMs, remain to be investigated in plants and fungi (Hu et al. 2005, Gibbs et al. 2014). The involvement of NO in the hypoxic signaling also deserves special attention. In animal cells, NO and RNS affect HIF expression, stability and activity in a complex manner, depending on local concentrations and cellular milieu (Hendrickson and R. 2015). Moreover, the Arg/N-degron pathway has been shown to act as a sensing mechanism to detect low NO levels both in animals and plants, although the response elicited by such conditions only marginally overlap with those to hypoxia (Puerta et al. 2019). The proteolytic element(s) positively affected by NO remains to be identified, but 490 it seems to lie elsewhere than thiol-dioxygenase activity (Puerta et al. 2019). Future efforts will likely shed light on defining the contribution of this signaling molecule to oxygen sensing in plants, animals and their ancestors.

On the evolutionary level, the commonality in $\mathrm{O}_{2}$-sensing mechanisms between the plant and animal kingdoms is striking but land plants and animals adopted alternative solutions to direct their primary hypoxia responses, even though their ancestors were likely equipped with the same repertoire of dioxygenases. The acquisition of $\mathrm{O}_{2}$-sensing function is likely associated with a reduction in oxygen 
affinity that matches variations in oxygen concentration occurring in the cells and tissues. These variations, in turn, are determined by environmental, ecological, and organismal features, such as metabolic rates and anatomy. Thus, fundamental differences in internal and external characteristics could have driven the distinct selection of biochemical pathways to direct selective proteolysis in these two systems - but what are these defining characteristics and what trade-offs followed with the different systems? Even for most modern multicellular organisms, we lack information on endogenous oxygen gradients and their fluctuations. On the other hand, many enzymes use oxygen as a cofactor but appear not to contribute to oxygen sensing machineries. This either suggests that their oxygen sensing potential is unexplored or that their function is to catalyze other specific reactions, irrespective of the environment. Nevertheless, constraining the details and hierarchical order of oxygen sensing systems will allow explorations of whether components were shared by a common ancestor or shared after the divergence of the respective kingdoms.

Finally, expanding our understanding of the evolution of oxygen sensing, by learning from geological history, will allow identification of opportunities for further beneficial manipulation of these systems for both clinical and agricultural purposes. Already, synthetic biology approaches that involve interchange of regulatory modules between organisms from different kingdoms constitute an innovative strategy to adapt oxygen sensitivity and the magnitude of response machineries (Licausi and Giuntoli 2020). For example, transfer of oxygen sensing components from plant to yeast has contributed to defining features 515 of these systems and could readily help identify novel drugs that interfere with their functioning (Puerta et al. 2019). We advocate a shift in focus, away from exploring oxygen sensing as primarily a response to oxygen shortage for aerobic respiration, towards considering it as a mechanism that enables multicellularity to cope with and even utilize fluctuations in oxygen concentrations. We predict that this will reward us with new perspectives on their broad scope, and the challenges that multicellular life is exposed to, today as in geologic history. 


\section{References and Notes:}

2019. An award to oxygen sensing. Nature Biomedical Engineering 3:843-844.

Abbas, M., S. Berckhan, D. J. Rooney, D. J. Gibbs, J. Vicente Conde, C. Sousa Correia, G. W. Bassel, N. Marín-de la Rosa, J. León, D. Alabadí, M. A. Blázquez, and M. J. Holdsworth. 2015. Oxygen sensing coordinates photomorphogenesis to facilitate seedling survival. Current biology : CB 25:1483-1488.

Alberti, K. G. 1977. The biochemical consequences of hypoxia. Journal of Clinical Pathology s3-11:14.

António, C., C. Päpke, M. Rocha, H. Diab, A. M. Limami, T. Obata, A. R. Fernie, and J. T. van Dongen. 2016. Regulation of Primary Metabolism in Response to Low Oxygen Availability as Revealed by Carbon and Nitrogen Isotope Redistribution. Plant Physiology 170:43-56.

Arendt, D., J. M. Musser, C. V. H. Baker, A. Bergman, C. Cepko, D. H. Erwin, M. Pavlicev, G. Schlosser, S. Widder, M. D. Laubichler, and G. P. Wagner. 2016. The origin and evolution of cell types. Nature Reviews Genetics 17:744-757.

Bachmair, A., D. Finley, and A. Varshavsky. 1986. In vivo half-life of a protein is a function of its amino-terminal residue. 234:179-186.

Batie, M., J. Frost, M. Frost, J. W. Wilson, P. Schofield, and S. Rocha. 2019. Hypoxia induces rapid changes to histone methylation and reprograms chromatin. Science 363:1222.

Bell, G., and A. O. Mooers. 2008. Size and complexity among multicellular organisms. Biological Journal of the Linnean Society 60:345-363.

Bergman, N. M., T. M. Lenton, and A. J. Watson. 2004. COPSE: A new model of biogeochemical cycling over Phanerozoic time. American Journal of Science 304:397437.

Berkner, L. V., and L. C. Marshall. 1965. On the origin and rise of oxygen concentration in the Earth's atmosphere. Journal of the Atmospheric Sciences 22:225-261.

Bracken, C. P., A. O. Fedele, S. Linke, W. Balrak, K. Lisy, M. L. Whitelaw, and D. J. Peet. 2006. Cell-specific regulation of hypoxia-inducible factor (HIF)-1 $\alpha$ and HIF-2 $\alpha$ stabilization and transactivation in a graded oxygen environment. Journal of Biological Chemistry 281:22575-22585.

Bui, L. T., G. Novi, L. Lombardi, C. Iannuzzi, J. Rossi, A. Santaniello, A. Mensuali, F. Corbineau, B. Giuntoli, P. Perata, M. Zaffagnini, and F. Licausi. 2019. Conservation of ethanol fermentation and its regulation in land plants. Journal of Experimental Botany 70:1815-1827.

555 Butterfield, N. J. 2015. Early evolution of the Eukaryota. 58:5-17.

Canfield, D. E. 2014. Proterozoic atmospheric oxygen. Treatise on Geochemistry. Elsevier Science.

Chakraborty, A. A., T. Laukka, M. Myllykoski, A. E. Ringel, M. A. Booker, M. Y. Tolstorukov, Y. J. Meng, S. R. Meier, R. B. Jennings, A. L. Creech, Z. T. Herbert, S. K. McBrayer, B. A. Olenchock, J. D. Jaffe, M. C. Haigis, R. Beroukhim, S. Signoretti, P. Koivunen, and W. G. Kaelin. 2019. Histone demethylase KDM6A directly senses oxygen to control chromatin and cell fate. Science 363:1217.

Chen, R., U. H. Lai, L. Zhu, A. Singh, M. Ahmed, and N. R. Forsyth. 2018. Reactive Oxygen Species Formation in the Brain at Different Oxygen Levels: The Role of Hypoxia Inducible Factors. 6.

Choi, W.-G., and D. M. Roberts. 2007. Arabidopsis NIP2;1, a Major Intrinsic Protein Transporter of Lactic Acid Induced by Anoxic Stress. 282:24209-24218.

Chowdhury, R., R. Sekirnik, N. C. Brissett, T. Krojer, C.-h. Ho, S. S. Ng, I. J. Clifton, W. Ge, N. J. Kershaw, G. C. Fox, J. R. C. Muniz, M. Vollmar, C. Phillips, E. S. Pilka, K. L. Kavanagh, F. von Delft, U. Oppermann, M. A. McDonough, A. J. Doherty, and C. J. Schofield. 2014. Ribosomal oxygenases are structurally conserved from prokaryotes to humans. Nature 510:422-426.

Cockman, M. E., K. Lippl, Y.-M. Tian, H. B. Pegg, W. D. J. Figg, M. I. Abboud, R. Heilig, R. Fischer, J. Myllyharju, C. J. Schofield, and P. J. Ratcliffe. 2019. Lack of activity of 
recombinant HIF prolyl hydroxylases (PHDs) on reported non-HIF substrates. eLife 8:e46490.

Cohen, E., and H. Kende. 1987. In vivo 1-aminocyclopropane-1-carboxylate synthase activity in internodes of deepwater rice : enhancement by submergence and low oxygen levels. Plant Physiology 84:282-286.

Comino-Mendez, I., A. A. de Cubas, C. Bernal, C. Alvarez-Escola, C. Sanchez-Malo, C. L. Ramirez-Tortosa, S. Pedrinaci, E. Rapizzi, T. Ercolino, G. Bernini, A. Bacca, R. Leton, G. Pita, M. R. Alonso, L. J. Leandro-Garcia, A. Gomez-Grana, L. Inglada-Perez, V. Mancikova, C. Rodriguez-Antona, M. Mannelli, M. Robledo, and A. Cascon. 2013. Tumoral EPAS1 (HIF2A) mutations explain sporadic pheochromocytoma and paraganglioma in the absence of erythrocytosis. Hum Mol Genet 22:2169-2176.

Covello, K. L., J. Kehler, H. Yu, J. D. Gordan, A. M. Arsham, C.-J. Hu, P. A. Labosky, M. C. Simon, and B. Keith. 2006. HIF-2 $\alpha$ regulates Oct-4: effects of hypoxia on stem cell function, embryonic development, and tumor growth. Genes \& Development 20:557570.

Dahl, T. W., E. U. Hammarlund, A. D. Anbar, D. P. G. Bond, B. C. Gill, G. W. Gordon, A. H. Knoll, A. T. Nielsen, N. H. Schovsbo, and D. E. Canfield. 2010. Devonian rise in atmospheric oxygen correlated to the radiations of terrestrial plants and large predatory fish. Proceedings of the National Academy of Sciences 107:17911-17915.

Das, B., R. Bayat-Mokhtari, M. Tsui, S. Lotfi, R. Tsuchida, D. W. Felsher, and H. Yeger. 2012. HIF-2alpha suppresses p53 to enhance the stemness and regenerative potential of human embryonic stem cells. Stem Cells 30:1685-1695.

Dashko, S., N. Zhou, C. Compagno, and J. Piškur. 2014. Why, when, and how did yeast evolve alcoholic fermentation? FEMS Yeast Research 14:826-832.

Dengler, V. L., M. Galbraith, and J. M. Espinosa. 2014. Transcriptional regulation by hypoxia inducible factors. Critical Reviews in Biochemistry and Molecular Biology 49:1-15.

Dickinson, D. J., W. J. Nelson, and W. I. Weis. 2011. A Polarized Epithelium Organized by $\beta$ and $\alpha$-Catenin Predates Cadherin and Metazoan Origins. 331:1336-1339.

Dissmeyer, N. 2019. Conditional Protein Function via N-Degron Pathway-Mediated Proteostasis in Stress Physiology. 70:83-117.

Epstein, A. C., J. M. Gleadle, L. A. McNeill, K. S. Hewitson, J. O'Rourke, D. R. Mole, M. Mukherji, E. Metzen, M. I. Wilson, A. Dhanda, Y. M. Tian, N. Masson, D. L. Hamilton, P. Jaakkola, R. Barstead, J. Hodgkin, P. H. Maxwell, C. W. Pugh, C. J. Schofield, and P. J. Ratcliffe. 2001. C. elegans EGL-9 and mammalian homologs define a family of dioxygenases that regulate HIF by prolyl hydroxylation. Cell 107:43-54.

610 Espenshade, P. J., and A. L. Hughes. 2007. Regulation of Sterol Synthesis in Eukaryotes. 41:401-427.

Farquhar, J., H. M. Bao, and M. Thiemens. 2000. Atmospheric influence of Earth's earliest sulfur cycle. Science 289:756-758.

Galkin, A., A. Higgs, and S. Moncada. 2007. Nitric oxide and hypoxia. Essays in Biochemistry 43:29-42.

Gibbs, D. J., and M. J. Holdsworth. 2020. Every Breath You Take: New Insights into Plant and Animal Oxygen Sensing. Cell 180:22-24.

Gibbs, D. J., N. Md Isa, M. Movahedi, J. Lozano-Juste, G. M. Mendiondo, S. Berckhan, N. Marín-de la Rosa, J. Vicente Conde, C. Sousa Correia, S. P. Pearce, G. W. Bassel, B. Hamali, P. Talloji, D. F. A. Tomé, A. Coego, J. Beynon, D. Alabadí, A. Bachmair, J. León, J. E. Gray, F. L. Theodoulou, and M. J. Holdsworth. 2014. Nitric oxide sensing in plants is mediated by proteolytic control of group VII ERF transcription factors. Molecular Cell 53:369-379.

Gibbs, D. J., H. M. Tedds, A. M. Labandera, M. Bailey, M. D. White, S. Hartman, C. Sprigg, S. L. Mogg, R. Osborne, C. Dambire, T. Boeckx, Z. Paling, L. Voesenek, E. Flashman, and M. J. Holdsworth. 2018. Oxygen-dependent proteolysis regulates the stability of angiosperm polycomb repressive complex 2 subunit VERNALIZATION 2. Nat Commun 9:5438. 
Giuntoli, B., V. Shukla, F. Maggiorelli, F. M. Giorgi, L. Lombardi, P. Perata, and F. Licausi. 2017. Age-dependent regulation of ERF-VII transcription factor activity in Arabidopsis thaliana. Plant, Cell \& Environment 40:2333-2346.

Graham, L. E., M. E. Cook, and J. S. Busse. 2000. The origin of plants: Body plan changes contributing to a major evolutionary radiation. 97:4535-4540.

Grahl, N., and R. A. Cramer, Jr. 2010. Regulation of hypoxia adaptation: an overlooked virulence attribute of pathogenic fungi? Medical Mycology 48:1-15.

Gregory, L., P. J. Came, and S. Brown. 2008. Stem cell regulation by JAK/STAT signaling in Drosophila. Seminars in Cell \& Developmental Biology 19:407-413.

Grosberg, R. K., and R. R. Strathmann. 2007. The Evolution of Multicellularity: A Minor Major Transition? Annual Review of Ecology, Evolution, and Systematics 38:621-654.

Gupta, K. J., L. A. J. Mur, A. Wany, A. Kumari, A. R. Fernie, and R. G. Ratcliffe. 2020. The role of nitrite and nitric oxide under low oxygen conditions in plants. 225:1143-1151.

Haase, V. H. 2013. Regulation of erythropoiesis by hypoxia-inducible factors. Blood reviews 27:41-53.

Hammarlund, E. 2019. Harnessing hypoxia as an evolutionary driver for complex life. Interface Focus (In Print).

Hammarlund, E., K. Stedingk, and S. Påhlman. 2018. Refined control of cell stemness allowed animal evolution in the oxic realm. Nature Ecology \& Evolution.

Hancock, R. L., K. Dunne, L. J. Walport, E. Flashman, and A. Kawamura. 2015. Epigenetic regulation by histone demethylases in hypoxia. Epigenomics 7:791-811.

Hancock, R. L., N. Masson, K. Dunne, E. Flashman, and A. Kawamura. 2017. The Activity of JmjC Histone Lysine Demethylase KDM4A is Highly Sensitive to Oxygen Concentrations. ACS Chemical Biology 12:1011-1019.

Hattori, Y., K. Nagai, S. Furukawa, X.-J. Song, R. Kawano, H. Sakakibara, J. Wu, T. Matsumoto, A. Yoshimura, H. Kitano, M. Matsuoka, H. Mori, and M. Ashikari. 2009. The ethylene response factors SNORKEL1 and SNORKEL2 allow rice to adapt to deep water. Nature 460:1026-1030.

He, C., S. A. Finlayson, M. C. Drew, W. R. Jordan, and P. W. Morgan. 1996. Ethylene Biosynthesis during Aerenchyma Formation in Roots of Maize Subjected to Mechanical Impedance and Hypoxia. 112:1679-1685.

Hendrickson, M., and P. R. 2015. Crosstalk between nitric oxide and hypoxia-inducible factor signaling pathways: an update. Research and Reports in Biochemistry 5:147-161.

Hirsila, M., P. Koivunen, V. Gunzler, K. I. Kivirikko, and J. Myllyharju. 2003. Characterization of the human prolyl 4-hydroxylases that modify the hypoxia-inducible factor. J Biol Chem 278:30772-30780.

Holdsworth, M. J., and D. J. Gibbs. 2020. Comparative Biology of Oxygen Sensing in Plants and Animals. Current Biology 30:R362-R369.

Holmquist-Mengelbier, L., E. Fredlund, T. Löfstedt, R. Noguera, S. Navarro, H. Nilsson, A. Pietras, J. Vallon-Christersson, A. Borg, K. Gradin, L. Poellinger, and S. Påhlman. 2006. Recruitment of HIF-1 $\alpha$ and HIF-2 $\alpha$ to common target genes is differentially regulated in neuroblastoma: HIF-2 $\alpha$ promotes an aggressive phenotype. Cancer Cell 10:413-423.

Hu, R.-G., J. Sheng, X. Qi, Z. Xu, T. T. Takahashi, and A. Varshavsky. 2005. The N-end rule pathway as a nitric oxide sensor controlling the levels of multiple regulators. Nature 437:981-986.

Huang, Y., D. Chen, C. Liu, W. Shen, and Y. Ruan. 2016. Evolution and conservation of JmjC domain proteins in the green lineage. Molecular Genetics and Genomics 291:33-49.

Hughes, B. T., and P. J. Espenshade. 2008. Oxygen-regulated degradation of fission yeast SREBP by Ofd1, a prolyl hydroxylase family member. The EMBO Journal 27:14911501. Oxoglutarate-Dependent Oxygenases. Annu Rev Biochem 87:585-620. 
IUCN. 2014. The World Conservation Union. Red List of Threatened Species 2014.3. Summary Statistics for Globally Threatened Species. Table 1: Numbers of threatened species by major groups of organisms (1996-2014).

lyer, N. V., L. E. Kotch, F. Agani, S. W. Leung, E. Laughner, R. H. Wenger, M. Gassmann, J. D. Gearhart, A. M. Lawler, and Y. Y. Aimee. 1998. Cellular and developmental control of $\mathrm{O} 2$ homeostasis by hypoxia-inducible factor $1 \alpha$. Genes \& Development 12:149-162.

Jain, S., E. Maltepe, M. M. Lu, C. Simon, and C. A. Bradfield. 1998. Expression of ARNT, ARNT2, HIF1 alpha, HIF2 alpha and Ah receptor mRNAs in the developing mouse. Mech Dev 73:117-123.

Jögi, A., I. Øra, H. Nilsson, Å. Lindeheim, Y. Makino, L. Poellinger, H. Axelson, and S. Påhlman. 2002. Hypoxia alters gene expression in human neuroblastoma cells toward an immature and neural crest-like phenotype. Proceedings of the National Academy of Sciences 99:7021-7026.

Kaelin, W. G. J., and P. J. Ratcliffe. 2008. Oxygen Sensing by Metazoans: The Central Role of the HIF Hydroxylase Pathway. Molecular Cell 30:393-402.

Keith, B., R. S. Johnson, and M. C. Simon. 2011. HIF1a and HIF2a: sibling rivalry in hypoxic tumour growth and progression. Nature reviews. Cancer 12:9-22.

Kendall, B., C. T. Reinhard, T. W. Lyons, A. J. Kaufman, S. W. Poulton, and A. D. Anbar. 2010. Pervasive oxygenation along late Archaean ocean margins. Nature Geoscience 3:647-652.

Kerpen, L., L. Niccolini, F. Licausi, J. T. van Dongen, and D. A. Weits. 2019. Hypoxic Conditions in Crown Galls Induce Plant Anaerobic Responses That Support Tumor Proliferation. 10.

Klinkenberg, J., H. Faist, S. Saupe, S. Lambertz, M. Krischke, N. Stingl, A. Fekete, M. J. Mueller, I. Feussner, R. Hedrich, and R. Deeken. 2014. Two Fatty Acid Desaturases, STEAROYL-ACYL CARRIER PROTEIN $\triangle 9$-DESATURASE6 and FATTY ACID DESATURASE3, Are Involved in Drought and Hypoxia Stress Signaling in Arabidopsis Crown Galls. 164:570-583.

Knoll, A. H. 2011. The Multiple Origins of Complex Multicellularity. Annual Review of Earth and Planetary Sciences 39:217-239.

Knoll, A. H., and S. B. Carrol. 1999. Early animal evolution: emerging views from comparative biology and geology. Science 284:2130-2137.

Krause, A. J., B. J. W. Mills, S. Zhang, N. J. Planavsky, T. M. Lenton, and S. W. Poulton. 2018. Stepwise oxygenation of the Paleozoic atmosphere. Nature Communications 9:4081.

Krock, B. L., N. Skuli, and M. C. Simon. 2011. Hypoxia-induced angiogenesis: good and evil. Genes \& cancer 2:1117-1133.

Kump, L. R. 2008. The rise of atmospheric oxygen. Nature 451:277-278.

Lee, P. J., B.-H. Jiang, B. Y. Chin, N. V. Iyer, J. Alam, G. L. Semenza, and A. M. K. Choi. 1997. Hypoxia-inducible Factor-1 Mediates Transcriptional Activation of the Heme Oxygenase-1 Gene in Response to Hypoxia. 272:5375-5381.

Lendahl, U., K. L. Lee, H. Yang, and L. Poellinger. 2009. Generating specificity and diversity in the transcriptional response to hypoxia. Nature Reviews Genetics 10:821-832.

Lenton, T. M., T. W. Dahl, S. J. Daines, B. J. W. Mills, K. Ozaki, M. R. Saltzman, and P. Porada. 2016. Earliest land plants created modern levels of atmospheric oxygen. Proceedings of the National Academy of Sciences 113:9704-9709.

Li, Z., S. Bao, Q. Wu, H. Wang, C. Eyler, S. Sathornsumetee, Q. Shi, Y. Cao, J. Lathia, R. E. McLendon, A. B. Hjelmeland, and J. N. Rich. 2009. Hypoxia-Inducible Factors Regulate Tumorigenic Capacity of Glioma Stem Cells. Cancer Cell 15:501-513.

730 Licausi, F., and B. Giuntoli. 2020. Synthetic biology of hypoxia. n/a.

Licausi, F., B. Giuntoli, and P. Perata. 2020. Similar and Yet Different: Oxygen Sensing in Animals and Plants. Trends in Plant Science 25:6-9.

Licausi, F., M. Kosmacz, D. A. Weits, B. Giuntoli, F. M. Giorgi, L. A. C. J. Voesenek, P. Perata, and J. T. van Dongen. 2011. Oxygen sensing in plants is mediated by an $\mathrm{N}$-end rule pathway for protein destabilization. Nature 479:419. 
Loenarz, C., M. L. Coleman, A. Boleininger, B. Schierwater, P. W. Holland, P. J. Ratcliffe, and C. J. Schofield. 2011. The hypoxia-inducible transcription factor pathway regulates oxygen sensing in the simplest animal, Trichoplax adhaerens. EMBO reports 12:6370.

740 Loenarz, C., R. Sekirnik, A. Thalhammer, W. Ge, E. Spivakovsky, M. M. Mackeen, M. A. McDonough, M. E. Cockman, B. M. Kessler, P. J. Ratcliffe, A. Wolf, and C. J. Schofield. 2014. Hydroxylation of the eukaryotic ribosomal decoding center affects translational accuracy. 111:4019-4024.

Masson, N., T. P. Keeley, B. Giuntoli, M. D. White, M. L. Puerta, P. Perata, R. J. Hopkinson, E. Flashman, F. Licausi, and P. J. Ratcliffe. 2019. Conserved N-terminal cysteine dioxygenases transduce responses to hypoxia in animals and plants. 365:65-69.

McKeown, S. R. 2014. Defining normoxia, physoxia and hypoxia in tumours-implications for treatment response. The British Journal of Radiology 87:20130676.

Mohlin, S., A. Hamidian, and S. PåhIman. 2013. HIF2A and IGF2 Expression Correlates in Human Neuroblastoma Cells and Normal Immature Sympathetic Neuroblasts. Neoplasia 15:328-IN338.

Mohlin, S., K. von Stedingk, A. Pietras, and S. Påhlman. 2017a. No reason to reconsider HIF2 as an oncogene in neuroblastoma and other cancer forms. 114:E10856-E10858.

Mohlin, S., C. Wigerup, A. Jögi, and S. Påhlman. 2017b. Hypoxia, pseudohypoxia and cellular differentiation. Experimental Cell Research 356:192-196.

Morris, J. L., M. N. Puttick, J. W. Clark, D. Edwards, P. Kenrick, S. Pressel, C. H. Wellman, Z. Yang, H. Schneider, and P. C. J. Donoghue. 2018. The timescale of early land plant evolution. Proceedings of the National Academy of Sciences 115:E2274.

Mustroph, A., S. C. Lee, T. Oosumi, M. E. Zanetti, H. Yang, K. Ma, A. Yaghoubi-Masihi, T. Fukao, and J. Bailey-Serres. 2010. Cross-Kingdom Comparison of Transcriptomic Adjustments to Low-Oxygen Stress Highlights Conserved and Plant-Specific Responses. Plant Physiology 152:1484.

Muz, B., P. de la Puente, F. Azab, and A. K. Azab. 2015. The role of hypoxia in cancer progression, angiogenesis, metastasis, and resistance to therapy. Hypoxia (Auckland, N.Z.) 3:83-92.

Nursall, J. R. 1959. Oxygen as a Prerequisite to the Origin of the Metazoa. Nature 183:11701172.

Persson, C. U., K. von Stedingk, E. Fredlund, D. Bexell, S. Pahlman, C. Wigerup, and S. Mohlin. 2020. ARNT-dependent HIF-2 transcriptional activity is not sufficient to regulate downstream target genes in neuroblastoma. Exp Cell Res:111845.

Pietras, A., D. Gisselsson, I. Øra, R. Noguera, S. Beckman, S. Navarro, and S. Påhlman. 2008. High levels of HIF-2 $\alpha$ highlight an immature neural crest-like neuroblastoma cell cohort located in a perivascular niche. The Journal of Pathology 214:482-488.

Porter, S. M. 2004. The fossil record of early eukaryotic diversification. The Paleontological Society Papers 10:35-50.

Pucciariello, C., S. Parlanti, V. Banti, G. Novi, and P. Perata. 2012. Reactive oxygen speciesdriven transcription in Arabidopsis under oxygen deprivation. Plant Physiology 159:184-196.

Puerta, M. L., V. Shukla, L. Dalle Carbonare, D. A. Weits, P. Perata, F. Licausi, and B. Giuntoli. 2019. A Ratiometric Sensor Based on Plant N-Terminal Degrons Able to Report Oxygen Dynamics in Saccharomyces cerevisiae. Journal of Molecular Biology 431:2810-2820.

Pugh, C. W., C. C. Tan, R. W. Jones, and P. J. Ratcliffe. 1991. Functional analysis of an oxygen-regulated transcriptional enhancer lying 3 ' to the mouse erythropoietin gene. Proc Natl Acad Sci U S A 88:10553-10557.

Ryan, H. E., J. Lo, and R. S. Johnson. 1998. HIF-1a is required for solid tumor formation and embryonic vascularization. The EMBO journal 17:3005-3015.

Rytkönen, K. T., T. A. Williams, G. M. Renshaw, C. R. Primmer, and M. Nikinmaa. 2011. Molecular Evolution of the Metazoan PHD-HIF Oxygen-Sensing System. Molecular Biology and Evolution 28:1913-1926. 
Scheuermann, T. H., Q. Li, H. W. Ma, J. Key, L. Zhang, R. Chen, J. A. Garcia, J. Naidoo, J. Longgood, D. E. Frantz, U. K. Tambar, K. H. Gardner, and R. K. Bruick. 2013. Allosteric inhibition of hypoxia inducible factor-2 with small molecules. Nat Chem Biol 9:271-276.

Scotti, J. S., I. K. H. Leung, W. Ge, M. A. Bentley, J. Paps, H. B. Kramer, J. Lee, W. Aik, H. Choi, S. M. Paulsen, L. A. H. Bowman, N. D. Loik, S. Horita, C.-h. Ho, N. J. Kershaw, C. M. Tang, T. D. W. Claridge, G. M. Preston, M. A. McDonough, and C. J. Schofield. 2014. Human oxygen sensing may have origins in prokaryotic elongation factor $\mathrm{Tu}$ prolyl-hydroxylation. Proceedings of the National Academy of Sciences 111:13331.

Seagroves, T. N., H. E. Ryan, H. Lu, B. G. Wouters, M. Knapp, P. Thibault, K. Laderoute, and R. S. Johnson. 2001. Transcription factor HIF-1 is a necessary mediator of the pasteur effect in mammalian cells. Molecular and Cellular Biology 21:3436-3444.

Sebé-Pedrós, A., B. M. Degnan, and I. Ruiz-Trillo. 2017. The origin of Metazoa: a unicellular perspective. Nature Reviews Genetics 18:498.

Sekirnik, R., S. E. Wilkins, J. Bush, H. Tarhonskaya, M. Münzel, A. Hussein, E. Flashman, S. Mohammed, M. A. McDonough, C. Loenarz, and C. J. Schofield. 2018. YcfDRM is a thermophilic oxygen-dependent ribosomal protein uL16 oxygenase. Extremophiles 22:553-562.

Semenza, G. L., S. T. Koury, M. K. Nejfelt, J. D. Gearhart, and S. E. Antonarakis. 1991. Celltype-specific and hypoxia-inducible expression of the human erythropoietin gene in transgenic mice. Proc Natl Acad Sci U S A 88:8725-8729.

Shmakova, A., M. Batie, J. Druker, and S. Rocha. 2014. Chromatin and oxygen sensing in the context of JmjC histone demethylases. The Biochemical journal 462:385-395.

Shukla, V., L. Lombardi, S. Iacopino, A. Pencik, O. Novak, P. Perata, B. Giuntoli, and F. Licausi. 2019. Endogenous Hypoxia in Lateral Root Primordia Controls Root Architecture by Antagonizing Auxin Signaling in Arabidopsis. Molecular Plant 12:538551.

Siauciunaite, R., N. S. Foulkes, V. Calabrò, and D. Vallone. 2019. Evolution Shapes the Gene Expression Response to Oxidative Stress. International journal of molecular sciences 20:3040.

820 Simon, M. C., and B. Keith. 2008. The role of oxygen availability in embryonic development and stem cell function. Nature reviews Molecular cell biology 9:285-296.

Slesak, I., H. Slesak, and J. Kruk. 2012. Oxygen and hydrogen peroxide in the early evolution of life on earth: in silico comparative analysis of biochemical pathways. Astrobiology 12:775-784.

Sperling, E. A., A. H. Knoll, and P. R. Girguis. 2015. The Ecological Physiology of Earth's Second Oxygen Revolution. Annual Review of Ecology, Evolution, and Systematics 46:215-235.

Stajich, J. E., M. L. Berbee, M. Blackwell, D. S. Hibbett, T. Y. James, J. W. Spatafora, and J. W. Taylor. 2009. The fungi. Current biology : CB 19:R840-R845.

Taabazuing, C. Y., J. A. Hangasky, and M. J. Knapp. 2014. Oxygen sensing strategies in mammals and bacteria. Journal of inorganic biochemistry 133:63-72.

Tarhonskaya, H., R. Chowdhury, I. K. Leung, N. D. Loik, J. S. McCullagh, T. D. Claridge, C. J. Schofield, and E. Flashman. 2014. Investigating the contribution of the active site environment to the slow reaction of hypoxia-inducible factor prolyl hydroxylase domain 2 with oxygen. Biochem J 463:363-372.

Tarhonskaya, H., A. P. Hardy, E. A. Howe, N. D. Loik, H. B. Kramer, J. S. McCullagh, C. J. Schofield, and E. Flashman. 2015. Kinetic Investigations of the Role of Factor Inhibiting Hypoxia-inducible Factor (FIH) as an Oxygen Sensor. J Biol Chem 290:19726-19742.

Thienpont, B., J. Steinbacher, H. Zhao, F. D'Anna, A. Kuchnio, A. Ploumakis, B. Ghesquiere, L. Van Dyck, B. Boeckx, L. Schoonjans, E. Hermans, F. Amant, V. N. Kristensen, K. Peng Koh, M. Mazzone, M. Coleman, T. Carell, P. Carmeliet, and D. Lambrechts. 2016. Tumour hypoxia causes DNA hypermethylation by reducing TET activity. Nature 537:63-68.

Tian, H., R. E. Hammer, A. M. Matsumoto, D. W. Russell, and S. L. McKnight. 1998. The hypoxia-responsive transcription factor EPAS1 is essential for catecholamine 
homeostasis and protection against heart failure during embryonic development. Genes \& Development 12:3320-3324.

Tian, R., D. Yin, Y. Liu, I. Seim, S. Xu, and G. Yang. 2017. Adaptive Evolution of Energy Metabolism-Related Genes in Hypoxia-Tolerant Mammals. Frontiers in genetics 8:205-205.

Ullah, M. S., A. J. Davies, and A. P. Halestrap. 2006. The Plasma Membrane Lactate Transporter MCT4, but Not MCT1, Is Up-regulated by Hypoxia through a HIF-1adependent Mechanism. 281:9030-9037.

Uniacke, J., C. E. Holterman, G. Lachance, A. Franovic, M. D. Jacob, M. R. Fabian, J. Payette, M. Holcik, A. Pause, and S. Lee. 2012. An oxygen-regulated switch in the protein synthesis machinery. Nature 486:126-129.

Valentine, J. W., A. G. Collins, and C. P. Meyer. 1994. Morphological Complexity Increase in Metazoans. Paleobiology 20:131-142.

Valzania, L., K. L. Coon, K. J. Vogel, M. R. Brown, and M. R. Strand. 2018. Hypoxia-induced transcription factor signaling is essential for larval growth of the mosquito Aedes aegypti. Proc Natl Acad Sci U S A 115:457-465.

van Dongen, J. T., and F. Licausi. 2015. Oxygen Sensing and Signaling. Annual Review of Plant Biology 66:345-367.

Varshavsky, A. 2019. N-degron and C-degron pathways of protein degradation. Proceedings of the National Academy of Sciences 116:358.

Waldbauer, J. R., D. K. Newman, and R. E. Summons. 2011. Microaerobic steroid biosynthesis and the molecular fossil record of Archean life. Proceedings of the National Academy of Sciences 108:13409-13414.

Webster, W. S., and D. Abela. 2007. The effect of hypoxia in development. Birth Defects Research Part C: Embryo Today: Reviews 81:215-228.

Weits, D. A., B. Giuntoli, M. Kosmacz, S. Parlanti, H.-M. Hubberten, H. Riegler, R. Hoefgen, P. Perata, J. T. van Dongen, and F. Licausi. 2014. Plant cysteine oxidases control the oxygen-dependent branch of the $\mathrm{N}$-end-rule pathway. Nature Communications 5:3425.

Weits, D. A., A. B. Kunkowska, N. C. W. Kamps, K. M. S. Portz, N. K. Packbier, Z. Nemec Venza, C. Gaillochet, J. U. Lohmann, O. Pedersen, J. T. van Dongen, and F. Licausi. 2019. An apical hypoxic niche sets the pace of shoot meristem activity. Nature 569:714-717.

Weits, D. A., J. T. van Dongen, and F. Licausi. 2020. Molecular oxygen as a signaling component in plant development. New Phytologist $\mathbf{n} / \mathbf{a}$.

Westerlund, I., Y. Shi, K. Toskas, S. M. Fell, S. Li, O. Surova, E. Södersten, P. Kogner, U. Nyman, S. Schlisio, and J. Holmberg. 2017. Combined epigenetic and differentiationbased treatment inhibits neuroblastoma tumor growth and links HIF2 $\alpha$ to tumor suppression. 114:E6137-E6146.

White, M. D., J. Kamps, S. East, L. J. Taylor Kearney, and E. Flashman. 2018. The plant cysteine oxidases from Arabidopsis thaliana are kinetically tailored to act as oxygen sensors. J Biol Chem 293:11786-11795.

White, M. D., M. Klecker, R. J. Hopkinson, D. A. Weits, C. Mueller, C. Naumann, R. O'Neill, J. Wickens, J. Yang, J. C. Brooks-Bartlett, E. F. Garman, T. N. Grossmann, N. Dissmeyer, and E. Flashman. 2017. Plant cysteine oxidases are dioxygenases that directly enable arginyl transferase-catalysed arginylation of $\mathrm{N}$-end rule targets. Nat Commun 8:14690.

Whitman, W. B., D. C. Coleman, and W. J. Wiebe. 1998. Prokaryotes: The unseen majority. Proceedings of the National Academy of Sciences 95:6578-6583.

Xu, Y., Z. A. Wang, R. S. Green, and C. M. West. 2012. Role of the Skp1 prolylhydroxylation/glycosylation pathway in oxygen dependent submerged development of Dictyostelium. BMC Dev Biol 12:31.

Yamauchi, T., S. Shimamura, M. Nakazono, and T. Mochizuki. 2013. Aerenchyma formation in crop species: A review. Field Crops Research 152:8-16. 
Yang, W., C. Catalanotti, T. M. Wittkopp, M. C. Posewitz, and A. R. Grossman. 2015. Algae after dark: mechanisms to cope with anoxic/hypoxic conditions. The Plant Journal 82:481-503.

Zaidi, M., F. Fu, D. Cojocari, T. D. McKee, and B. G. Wouters. 2019. Quantitative Visualization of Hypoxia and Proliferation Gradients Within Histological Tissue Sections. 7.

Zhuang, Z., C. Yang, F. Lorenzo, M. Merino, T. Fojo, E. Kebebew, V. Popovic, C. A. Stratakis, J. T. Prchal, and K. Pacak. 2012. Somatic HIF2A gain-of-function mutations in paraganglioma with polycythemia. The New England journal of medicine 367:922-930. 
Acknowledgments: The authors thank Kenneth Pienta and Sven Påhlman for essential and constructive discussions and the Ella Maru Studio for assistance to illustrate Fig. 4. We would like to apologise to those whose work we were not able to cite due to space limitations but acknowledge the contribution you have made to the field. Funding: The Swedish Research Council (EUH), the Crafoord Foundation (EUH, SM), The Villum Foundation grant 16518 (EUH), the Swedish Cancer Society (SM), the Swedish Childhood Cancer Fund (SM), the Engineering and Physical Sciences Research Council (EF), the European Research Council (EF), and the Italian Ministry of University and Research (FL). Author contributions: EUH and FL conceptualized the review and EUH, EF, SM, and FL wrote the paper. Competing interests: The authors declare no competing interests. 
Fig. 1: Increasing complexity of oxygen sensing mechanisms and the extent of complexity within multicellular organisms over Earth's history of 4.6 billion years (giga annum, Ga). Enzymes (diamonds) and substrates (circles) form components of oxygen sensing mechanisms, based on thiol dioxygenases (orange outlines) and Fe(II)/2-OG-dependent dioxygenases (brown outlines). We depict the presumed appearance of the oxygen sensing components during the divergence of the eukaryotic animal, plant and fungi kingdoms (dashed lineages). The onset of the respective diversifications of fungi (Basidiomycota and Ascomycota) with differentiated tissues (brown; Stajich et al. 2009), invertebrate animals, vertebrates, and mammals (purple; Knoll and Carrol 1999), and green, land, and vascular plants (green; Morris et al. 2018). Observations of enzymes (Enz.) and substrates (Subst.) for each group of organisms include when found in sequences, when determined to have an oxygen sensing role, or both. Complexity of tissues for each group of organisms is represented by their maximum number of different cell types (diversity) (Valentine et al. 1994, Bell and Mooers 2008, Arendt et al. 2016). Reconstructions of atmospheric oxygen levels in the past, that constrain ranges of min-max oxygenation, agree upon a maximum oxygenation of $\sim 0.2$ of modern levels (< approximately $4 \% \mathrm{O} 2$ ) for the Mesoproterozoic Era (1.6-1.0 Ga) and Neoproterozoic Era (1.0-0.6) (thick blue field). The maximum oxygenation of $\sim 4 \%$ is presumed for the time interval when eukaryotic kingdoms diversified $(0.8-0.5 \mathrm{Ga})$, meaning the evolution of oxygen sensing mechanisms is rooted in hypoxic conditions (Kump 2008, Canfield 2014). Geochemical indications and modelling efforts indicate that high atmospheric oxygen concentrations, as today, persisted at 2.5-2.0 Ga and then from 0.4 Ga (the Devonian Period) onwards (Farquhar et al. 2000, Bergman et al. 2004, Kump 2008, Dahl et al. 2010, Canfield 2014, Lenton et al. 2016).

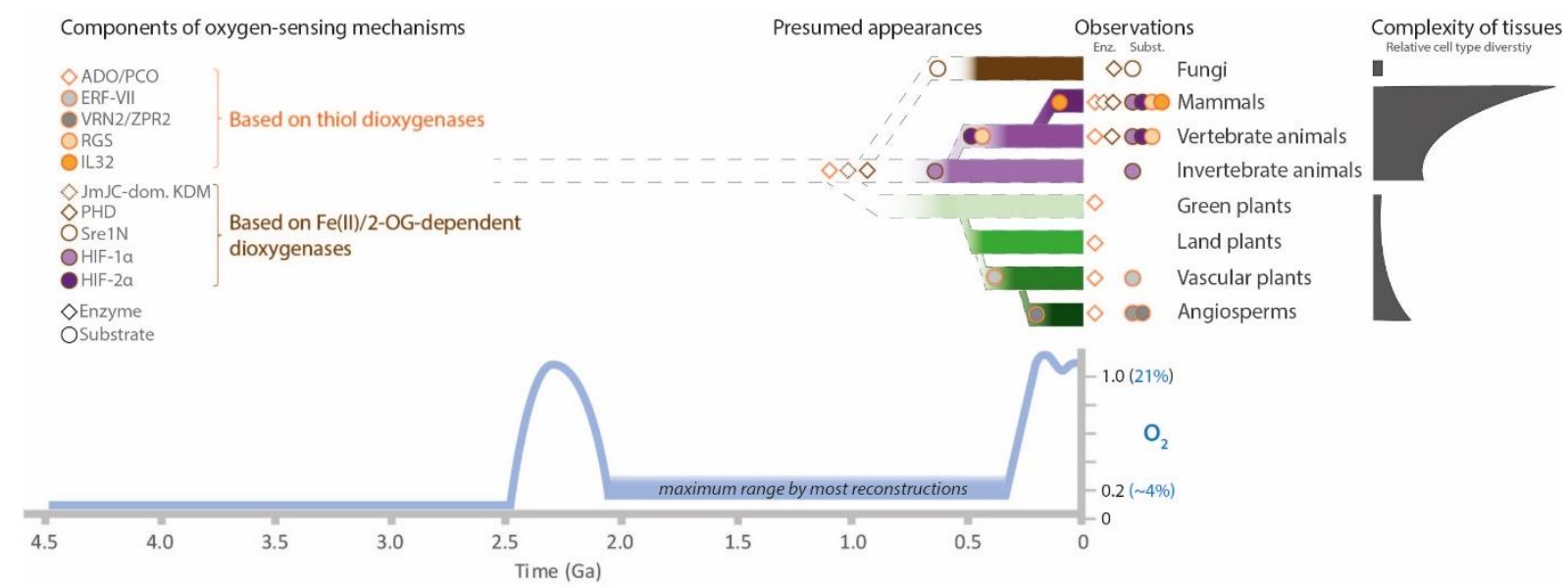


940 Fig. 2: Direct mechanisms for oxygen sensing and hypoxic signaling in A) complex multicellular organisms within the eukaryotic kingdoms; protozoa, fungi, vascular plants, and animals. B) The transducers of hypoxia response machineries: the Pro-containing proteins that may be hydroxylated and degraded in the presence of oxygen (blue field) or stabilized by hypoxia (white fields): S-phase kinaseassociated protein 1 (Skp1), sterol regulatory element-binding protein transcription factor (Sre1N) and Hypoxia inducible factor (HIF), or the Cys-initiating proteins Group VII Ethylene Response Factors (ERF-VII), Little Zipper Protein 2 (ZPR2), Vernalization 2 (VRN2), IL32 and RGS4/5. Histone (de)methylation can be also modulated in an oxygen-dependent manner in eukaryotes. C) The sensory components based on $\mathrm{Fe}(\mathrm{II}) / 2 \mathrm{OG}-d e p e n d e n t$ dioxygenases $\left(^{*}\right)$ are prolyl hydroxylases (PHD or Ofd1) or JmJC-domain containing histone lysine demethylases (KDMs). D) The sensory components based on thiol dioxygenases $\left({ }^{\S}\right)$ are plant cysteine oxidase (PCO) and 2-aminoethanethiol dioxygenase (ADO). In contrast, proteolysis (involving also proteins such as pF-box, UBR1, ATE, PRT6, and pVHL proteins and nitric oxide [NO]) and demethylation occur at relatively high oxygen concentrations (blue shading). Cellular responses at hypoxic conditions (hypoxic responses) are context and substrate dependent: When the stabilized protein is a transcription factor (Sre1N, ERF-VII and HIF- $\alpha$ (1)), hypoxia responsive genes are induced and the hypoxia response of different scope (length of black arrows). Also, of the PCO substrates in plants VRN2 (2) regulates chromatin condensation whereas ZPR2 (3) controls activity of transcription factors. Of the ADO substrates in animals, RGS4/5 (4) control G protein signaling, and IL32 (5) controls inflammation by interacting with an unknown receptor. In animals, demethylation by the JmJC-containing domain KDMs can both activate and silence gene expression in an oxygen-dependent manner.

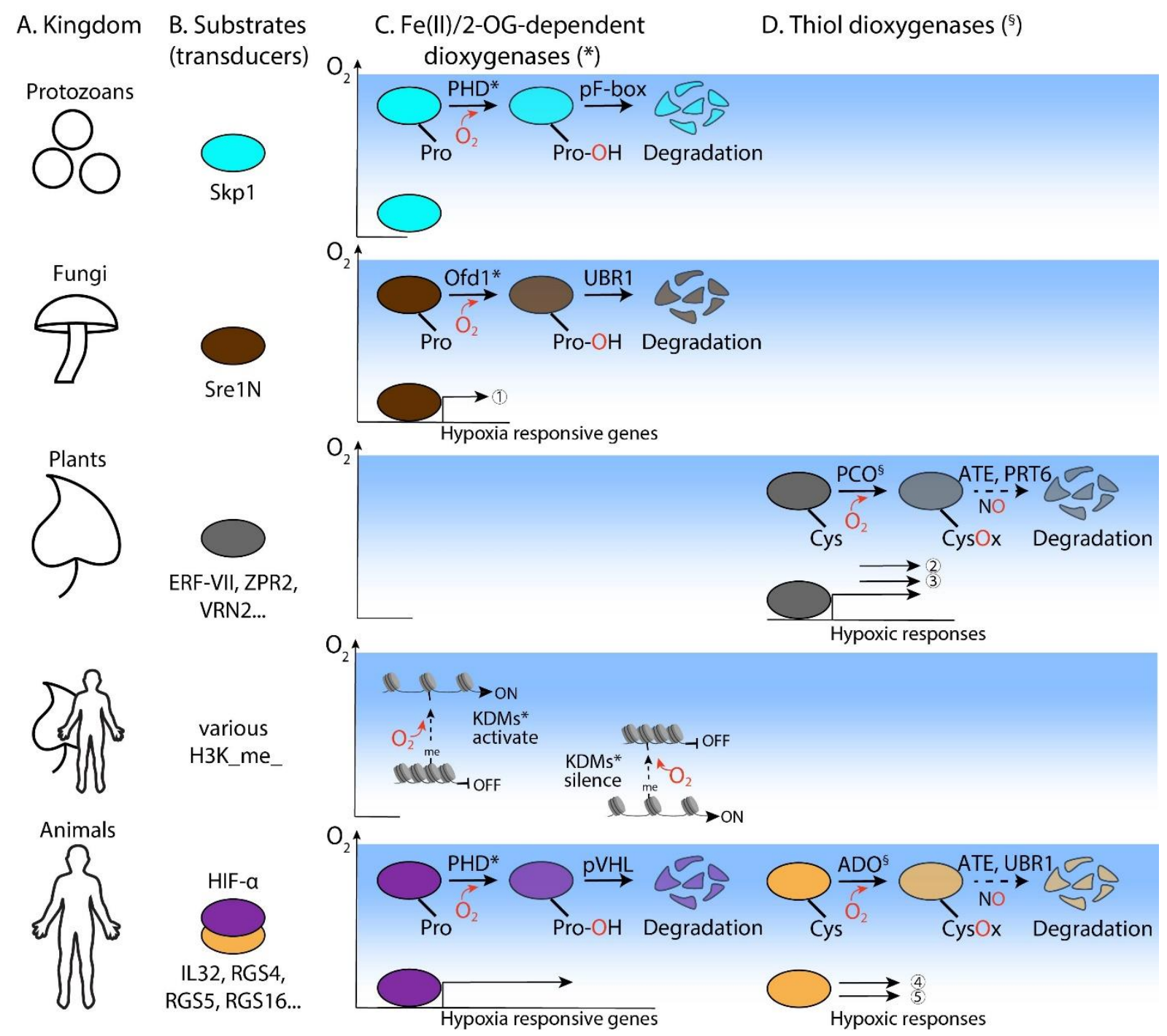


Fig. 3: Some of the roles that hypoxia-response machineries appear to be involved in across eukaryotic kingdoms, with representative roles listed as related to mediation of metabolism (battery), oxygen resupply (balloon), scavenging of ROS (explosion), or development and tissue maintenance (cogs).

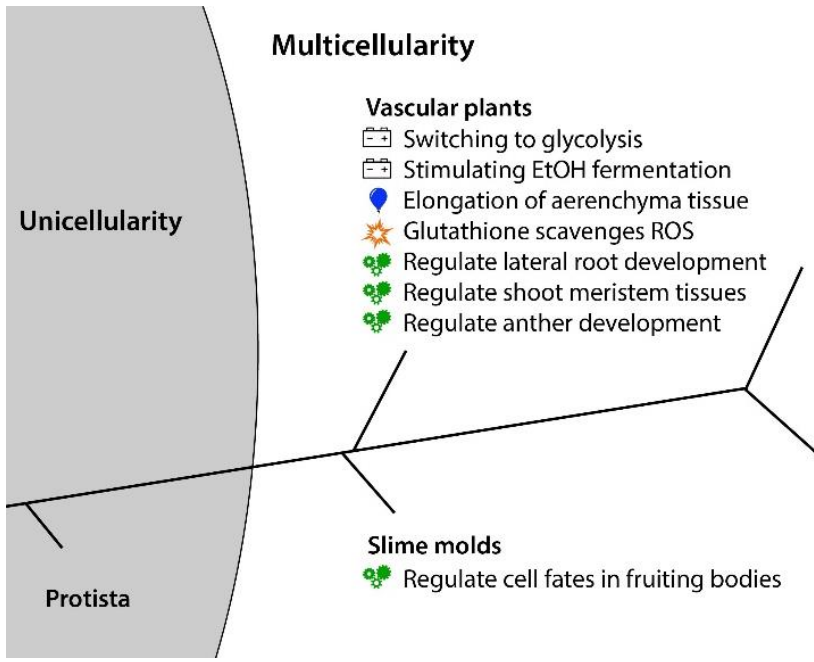

Animals

-7 Switching to glycolysis (also aerobic)

$-\rightarrow$ Regulating $\mathrm{pH}$ \& lactic fermentation

Driving angiogenesis

Promoting haematopoiesis

Klutathione scavenges ROS

Teroxidases scavenge ROS

Superoxide dismutase scavenges ROS

of Regulate organ development

o. Regulate wound healing

o: Induce cell de-differentiation

o: Promote cell stemness (also in cancer)

of Regulate apoptosis

Fungi

Hypoxia-responses involve:

Matching lipid synthesis

to nutrient supply

-- Metabolic adaptations

Responses to re-oxygenation

Scavenging of ROS

o. Development \& tissue maintenance 
Fig. 4: Oxygen sensing mechanisms across the eukaryotic kingdoms with complex multicellularity that converged to the recruitment of enzymatic control of the stability of regulatory proteins at specific endogenous oxygen concentrations (depicted for animals). Endogenous oxygen gradients (1) and the spatial position of perceiving cells (2) are stylized, with a dial (3) depicting the sensing (outer half circle) and response (inner half circle). In the dial, proteins are labelled as oxidized (Pro-OH/CysOx) at oxic conditions (blue), or non-oxidized (Cys/Pro) at hypoxia (black). The inner half circle of the dial represents the stabilization of a protein (half halo) or as a transcription factor (TF; pie chart, see Fig. 2 for color coding and substrates). Thiol-dioxygenases stabilize TFs in green plants (Viridiplantae) and 2-OG-dependent dioxygenases stabilize TFs in animals (Eumetazoa and Cnidaria) and Fungi. Protein stabilization (not TFs) is also regulated by thiol-dioxygenases in mammals and by 2-OG-oxygenases in slime molds.

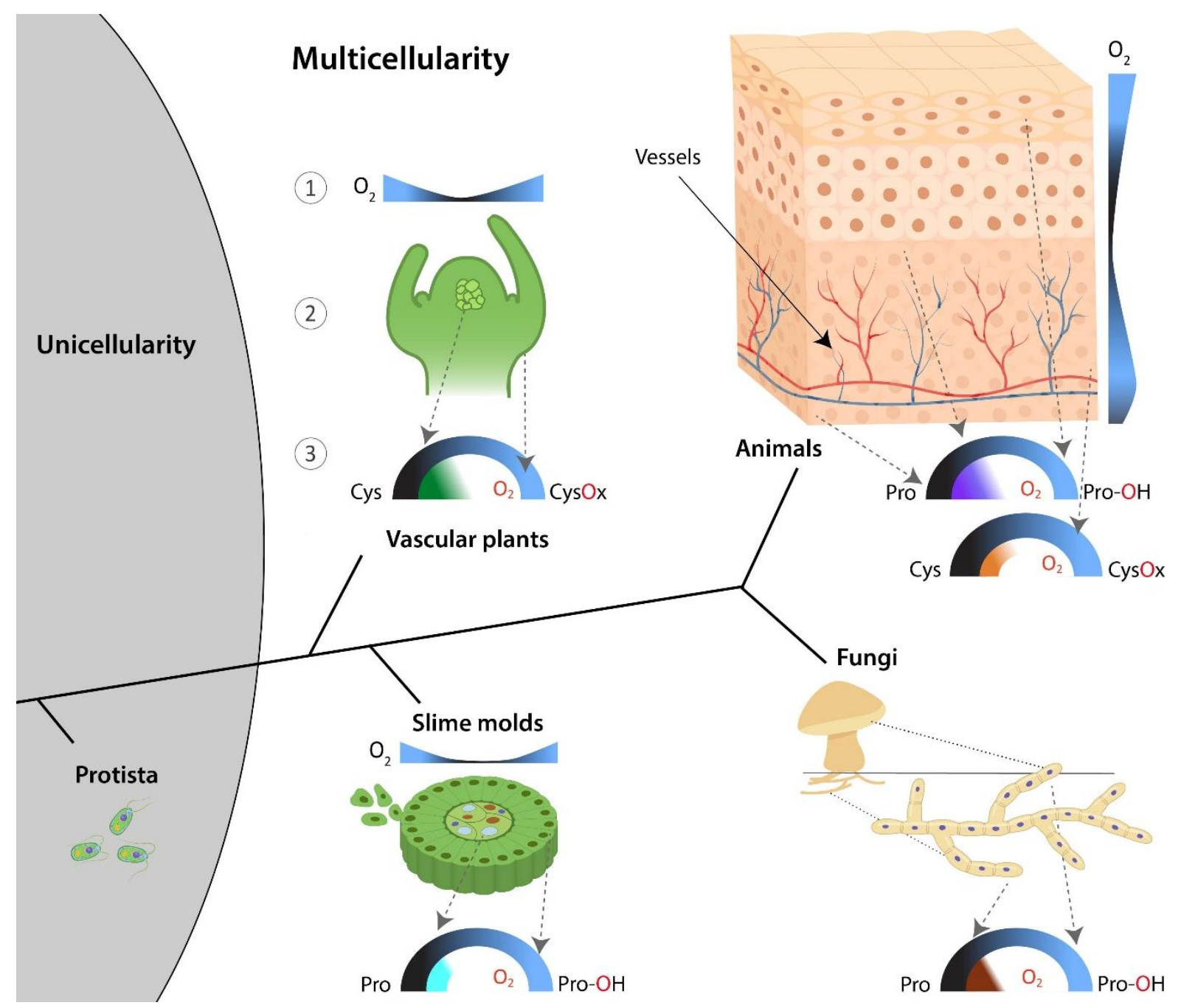


Cell fate: The future identity of a cell (or its daughter cells) and the accompanying phenotype or task to perform within its tissue and context.

Enzymatic proteolysis: Breakdown of proteins into peptides by the action of proteases, often organized in complexes, e.g. the proteasome. In cells, proteolysis is often directed by cascades of post-translational modifications, including ubiquitination, that label a protein for degradation.

Enzymes: Proteins that can catalyze a chemical reaction (biocatalyst) and thus offer a kinetic potential to chemical reactions. Oxygen-dependent enzymes discussed in this review include:

$\mathrm{Fe}$ (II)/2-oxoglutarate (2OG) dependent dioxygenase: Oxido-reductase enzymes that catalyze incorporation of oxygen atoms into a variety of substrates; 2-oxoglutarate is concomitantly converted to succinate and $\mathrm{CO}_{2}$.

Thiol dioxygenases: Fe(II) dependent enzymes that catalyze the oxygen-dependent oxidation of free thiols (-SH) to sulfinic acid $\left(-\mathrm{SO}_{2} \mathrm{H}\right)$.

PCO: Plant Cysteine Oxidases are a group of thiol dioxygenases that catalyze dioxygenation of cysteinyl (Cys) residues at the N-termini of substrate proteins, such as the ERF-VII transcription factors.

ADO: 2-aminoethanethiol dioxygenase is a thiol dioxygenase that regulates stability of $\mathrm{N}$ terminal Cys-initiating proteins IL32 and RGS4/5 in humans via Cys dioxygenation and the Ndegron pathway.

Eukaryotic kingdoms: Protista, Plantae, Animalia (Metazoa) and Fungi

1000 Eumetazoa: A basal animal clade and sister group to Porifera (sponges). Eumetazoans have either radial (e.g. cnidaria) or bilateral symmetry (invertebrates or vertebrates).

Hypoxia-response machinery: Consists of one component that perceive a decrease in oxygen availability (e.g. enzyme) and one that induces a response (e.g. transcription factor) to trigger cellular adaptation.

1005 Oxygen sensing: The ability to detect changes in the amount of oxygen and mount an adaptive response.

Redox: Chemical reactions where the oxidation states of atoms change.

Stemness: Cell ability of self-renewal by division and differentiation into specialized cell types.

Spatiotemporal division of cell fate: When cells in an organ perform different functions at the same time in a coordinated manner.

1010 Transcription factor: A protein that controls the rate of transcription of genetic information from DNA to mRNA. They bind to DNA in a sequence specific manner. The main transcription factors discussed in this review are:

HIFs (Hypoxia Inducible Factors): Members of the basic helix-loop-helix (bHLH) family, consisting of an alpha subunit and a beta unit (ARNT). Generally, the HIFs are constitutively expressed but their alpha subunit is degraded via $\mathrm{Fe}(\mathrm{II})-2 \mathrm{OG}$ dependent oxygenases in the presence of oxygen. 
ERF-VIIs (Group VII Ethylene Response Factors): Cys-initiating members of the ERF/APETALA2 (ERF/AP2) family. Some ERF-VIIs are constitutively expressed but degraded via the activity of PCOs in the presence of oxygen.

1020 Viridiplantae: Green plants, consisting of the clades Chlorophyta and Streptophyta (under which land plants (Embryophyta) and vascular plants (Tracheophyta) are subdivisions). A subdivision of vascular plants is flowering plants (Angiosperms). 